\title{
Modelling the dispersal of riverine fish larvae: from a raster- based analysis of movement patterns within a racetrack flume to a rheoreaction-based correlated random walk (RCRW) model approach
}

\begin{tabular}{|r|l|}
\hline Journal: & Canadian Journal of Fisheries and Aquatic Sciences \\
\hline Manuscript ID & cjfas-2016-0287.R1 \\
\hline Manuscript Type: & Article \\
\hline Date Submitted by the Author: & 23-Dec-2016 \\
\hline Complete List of Authors: & $\begin{array}{l}\text { Glas, Martin; Christian Doppler Laboratory for Advanced Methods in River } \\
\text { Monitoring, Modelling and Engineering, Institute of Water Management, } \\
\text { Hydrology and Hydraulic Engineering, Department of Water, Atmosphere } \\
\text { and Environment, BOKU-University of Natural Resources and Life Sciences } \\
\text { Vienna } \\
\text { Tritthart, Michael; Christian Doppler Laboratory for Advanced Methods in } \\
\text { River Monitoring, Modelling and Engineering, Institute of Water } \\
\text { Management, Hydrology and Hydraulic Engineering, Department of Water, } \\
\text { Atmosphere and Environment, BOKU-University of Natural Resources and } \\
\text { Life Sciences Vienna } \\
\text { Zens, Bernhard; Universitat Wien Fakultat fur Lebenswissenschaften, } \\
\text { Department of Limnology and Oceanography } \\
\text { Keckeis, Hubert; University of Vienna, ; } \\
\text { Lechner, Aaron; Department of Limnology and Bio-Oceanography, Faculty } \\
\text { of Life Sciences, University of Vienna } \\
\text { Kaminskas, Timothy; Australia Department of the Environment } \\
\text { Habersack, Helmut; Christian Doppler Laboratory for Advanced Methods in } \\
\text { River Monitoring, Modelling and Engineering, Institute of Water } \\
\text { Management, Hydrology and Hydraulic Engineering, Department of Water, } \\
\text { Atmosphere and Environment, BOKU-University of Natural Resources and } \\
\text { Life Sciences Vienna }\end{array}$ \\
\hline Keyword: & $\begin{array}{l}\text { 3D hydrodynamic model, particle tracing model, behaviour, orientation, } \\
\text { Chondrostoma nasus }\end{array}$ \\
\hline \hline
\end{tabular}

\section{SCHOLARONE"}


Modelling the dispersal of riverine fish larvae: from a raster-based analysis of movement patterns within a racetrack flume to a rheoreaction-based correlated random walk (RCRW) model approach

\section{Martin Glas}

Christian Doppler Laboratory for Advanced Methods in River Monitoring, Modelling and Engineering, Institute of Water Management, Hydrology and Hydraulic Engineering, Department of Water, Atmosphere and Environment, BOKUUniversity of Natural Resources and Life Sciences Vienna,

Muthgasse 107, 1190 Vienna, Austria

martin.glas@boku.ac.at

phone: 004313189900113

fax: 004313189900149

Michael Tritthart

Christian Doppler Laboratory for Advanced Methods in River Monitoring, Modelling and Engineering, Institute of Water Management, Hydrology and Hydraulic Engineering, Department of Water, Atmosphere and Environment, BOKUUniversity of Natural Resources and Life Sciences Vienna, Muthgasse 107, 1190 Vienna, Austria

michael.tritthart@boku.ac.at

Bernhard Zens

Department of Limnology and Bio-Oceanography, Faculty of Life Sciences, University of Vienna,

Althanstraße 14, 1090 Vienna, Austria

a0707530@unet.univie.ac.at

Hubert Keckeis

Department of Limnology and Bio-Oceanography, Faculty of Life Sciences, University of Vienna,

Althanstraße 14, 1090 Vienna, Austria

hubert.keckeis@univie.ac.at 
Aaron Lechner

Department of Limnology and Bio-Oceanography, Faculty of Life Sciences, University of Vienna,

Althanstraße 14, 1090 Vienna, Austria

aaron.lechner@univie.ac.at

Timothy Kaminskas

Australian Department of the Environment and Energy

John Gorton Building, King Edward Terrace, Parkes ACT 2600, Australia

tim.kaminskas@environment.gov.au

Helmut Habersack

Christian Doppler Laboratory for Advanced Methods in River Monitoring, Modelling and Engineering, Institute of Water Management, Hydrology and Hydraulic Engineering, Department of Water, Atmosphere and Environment, BOKUUniversity of Natural Resources and Life Sciences Vienna,

Muthgasse 107, 1190 Vienna, Austria

helmut.habersack@boku.ac.at

special issue: "Dispersal during Early Life History of Fish" 


\begin{abstract}
Recruitment of Chondrostoma nasus (Linnaeus 1758) and similar fish species in rivers is related to spatio-temporal linkages between larval hatching and nursery habitats. Active swimming behaviour contradicts the assumption that passive particle tracing models can serve as a proxy for larval dispersal models. A racetrack flume with an inshore area of near-natural slope was created to observe individual larval trajectories. A new three-step, raster-based analysis was developed to distinguish four types of movement patterns: active upstream, active downstream, activepassive and passive. Both larval developmental stage- and release site-specific occurrences of these movement patterns were experimentally found for nine flow velocity classes $\left(\leq 0.225 \mathrm{~m} \mathrm{~s}^{-1}\right)$. These current-induced movement patterns, and evaluated durations within them, were used to develop a biased and correlated random walk (BCRW) model which includes rheoreaction-a key behavioural response of fish to flow within rivers. The study introduces the concept and application of a rheoreaction-based correlated random walk (RCRW) model which, coupled with a 3D hydrodynamic model, allows prediction of the spatio-temporal effects of various river discharges, morphologies and restoration scenarios on larval fish dispersal.
\end{abstract}




\section{Introduction}

Recent studies of fish larvae highlight the impact that active swimming behaviour has on their dispersal patterns in both freshwater (Lechner et al. 2016; Lechner et al. 2014b; Schludermann 2012) and marine environments (Leis 2006; Fisher et al. 2000; Leis and Carson-Ewart 1997). Dispersal modes of fish during the crucial larval phase of their lifecycle is an important factor in recruitment, and is governed by abiotic triggers (e.g. hydrology and hydraulics: Pavlov (1994); and discharge: Lechner et al. (this issue); Korman et al. (2004); Reichard and Jurajda (2004)), in combination with biotic triggers (e.g. physiology and behaviour: Gaudin and Sempeski (2001); Heggenes and Dokk (2001); Pavlov (1994)). In a study on juvenile fish movement, Pavlov et al. (2008) concluded that micro-scale habitat heterogeneity, interacting with individual behavioural variability within fish populations, could affect the proportion of resident to migratory fish in a river. Hence, rheoreaction, defined as active fish behaviour induced by the current (Pavlov 2010), refutes the implementation of passive particles as a proxy for fish larvae (Lechner et al. 2014a; Schludermann et al. 2012; Stoll and Beek 2012). As individual-based models (IBM) and correlated random walk models (CRW), introduced by Fraenkel and Gunn (1940), gain acceptance in studies of larval dispersal in oceanic environments by coupling abiotic and biotic factors (Peck and Hufnagl 2012; Miller 2007; Werner et al. 2001b), the implementation of larval orientation and navigation behaviour into these models substantially enhances assessment of the spatiotemporal linkages between spawning and nursery areas.

Currently, IBM and CRW models range from dealing with simple vertical distribution (Vikebø 2007; Werner et al. 1993), to highly-coupled models using various biological factors (e.g. mortality, feeding, prey aspects: Paris et al. 2007; Werner et al. 
$2001 a, b)$, and to models investigating cues affecting fish movement behaviours (Armsworth 2000). The latter have become a focus in studies on biased and correlated random walk (BCRW) models, by using either fixed compass directions (Béguer-Pon 2015) or environmental cues, for example, ambient reef sound (Staaterman 2013; Codling 2004; Werner et al. 1993), or prey occurrence (Matanoski and Hood 2006). Relating to reef sounds, Staaterman et al. (2012) linked the navigation approach from Codling (2004) with a three-dimensional (3D), coupled biophysical model (Paris 2013), and found higher settlement rates for oriented larvae. Models of larval fish dispersal patterns within riverine ecosystems are rare (e.g. Wolter \& Sukhodolov 2008; Korman et al. 2004; Cowan et al. 1993). However, models which include rheoreaction have been developed for several organisms and their larval developmental stages (Marcos et al. 2012; Mork et al. 2012; Booker et al. 2008).

Kingsford et al. (2002) recommended obtaining high-resolution spatial information on navigation, at scales of less than one meter, before implementation into models of larval fish dispersal (from meters to kilometers). In this regard, there are field studies which have included continuously tracked fish larvae (Leis et al. 2014; Irisson et al. 2009; Leis 2006). There are also flume experiments on larval fish behaviour using manipulated hydraulic conditions (e.g. Atema et al. 2002; Stobutzki and Bellwood 1994; Arnold 1968). Flore et al. (2001) studied swimming speed for nase carp larvae (Chondrostoma nasus), and found a positive linear relationship between larval size (total length) and larval maximum sustainable water velocity (MSWV, Kaufmann (1990)). Pavlov (1994) introduced three downstream movement patterns for larval and juvenile fish: (i) active downstream $(A d)$, orientation in the direction of flow and fish swim with the flow (speed over ground is greater than flow); (ii) active-passive 
(Ap), orientation against the direction of flow and fish swim against the flow (speed over ground is less than flow), and; (iii) passive $(P)$, random orientation relative to the direction of flow and fish passively drift with the flow (speed over ground is equal to flow). Zens et al. (this issue) have focused on stage-specific behavioural aspects of rheoreaction for nase carp larvae according to Pavlov's definition (Pavlov 1994) and for different flow scenarios. A method for the detection of movement patterns has been presented, based on averaged swimming speeds in relation to current velocity and orientation of larvae relative to the current vector. Swimming speeds have been assumed with a fixed path length of $10 \mathrm{~cm}$ per observation grid cell. Active-passive movement was found to be the dominating downstream movement pattern of different developmental stages within all flow scenarios.

Experimental studies on microorganisms have shown that, typically, swimming speeds are either exponentially (e.g. Codling and Hill 2005; Hill and Häder 1997) or normally distributed (Bearon and Grunbaum 2008). Codling et al. (2010) found that a variable swimming speed can significantly change the spatial distribution of microorganisms when implemented in CRW models.

While numerous IBM and CRW models, covering various aspects of the larval fish lifecycle, have been developed and successfully used to explain processes regarding larval dispersal patterns, the literature does not describe models covering rheoreaction for larval movement and dispersal. Studies involving meso-scale flume experiments (300-500 times larval fish body length) aimed at improving larval dispersal models, and which use rheoreaction at an inshore area together with nearly continuously observed trajectories, are not reported in the literature. Willis (2011) suggests that track analysis and track replication within models to understand the factors influencing fish navigation, should be a focus of future research. In 
addition, Lechner et al. (2016) have encouraged further research into rheoreaction settlement cues for drifting fish larvae in running waters.

Eurasian, African and North American rivers are highly populated by cyprinids (Nelson et al. 2016). The nase carp (Chondrostoma nasus (Linnaeus 1758)) is a wide-spread and characteristic riverine cyprinid species in Central- and Eastern Europe (Lelek 1987), and is considered as target species in many studies (Le Pichon 2016; Hauer et al. 2008; Keckeis et al. 1996) for European rivers. During the last century, it's populations declined drastically due to pollution, river regulation and damming (Kirchhofer 1996; Peňáz et al. 1996; Lusk and Halačka 1995). Nase carp spawn at gravel bed of rivers. After emergence larvae are exposed to the flow and disperse downstream to what we presume suitable nursery habitats at natural inshore zones. Habitat connectivity between hatching and nursery habitats is therefore a crucial factor in their life cycle.

In this study, raster-based observed trajectories of nase carp larvae (Chondrostoma nasus (Linnaeus 1758)) within a racetrack flume, were used to analyse upstream and downstream larval movement patterns (rheoreaction) at a micro-scale, based on Pavlov's definition of movement patterns (Pavlov 1994). With the aim of developing a rheoreaction-based larval dispersal model, a key tool in analysing habitat connectivity, we investigated whether the observed movement patterns of fish larvae were dependent on: (a) flow velocity as an abiotic factor at a micro-scale; (b) ontogeny and concomitant change in larval swimming ability; (c) the release site as the initial point representing distinct areas of emergence; and (d) diel (day and night) patterns characterised by a nocturnal increase in drift (Reichard et al. 2002; Johnston 1995). From this, we developed a rheoreaction-based CRW model dependent on Pavlov's movement patterns, where rheoreaction was implemented as 
the combination of a bias of movement direction (BCRW approach) and a distinct ratio of larval swimming speed to flow velocity.

\section{Material and Methods}

This investigation involved the observation of larval fish trajectories within a flume experiment. The aim was to replicate larval trajectories for several scenarios involving flow velocity, diel patterns, inshore and offshore release sites and several larval developmental stages. The three-dimensional flow field was computed with a 3D hydrodynamic model and overlaid with an alphanumeric observation raster to connect the observed larval trajectories with flow properties. To Pavlov's three movement patterns, Zens et al. (this issue) added a fourth-active upstream $(A u)$ : orientation against the direction of flow and larvae swim against the flow (speed over ground is greater than flow)-to capture all observed movements within the study. A new three-step, raster-based analysis, including movement direction, numerical particle tracing and orientation to flow direction as reference points, has been established to distinguish between the four movement patterns ( $A u, A d, A p$, and $P$ ). Taking into account these four patterns, a new concept for a BCRW model has been developed that also considers rheoreaction.

\section{Racetrack flume}

The racetrack flume in Figure 1 was constructed in the Hydraulic Engineering Laboratory of the University of Natural Resources and Life Sciences, Vienna, Austria. It consisted of two straight sections $2 \mathrm{~m}$ long and two half-circle bends at each end with an outer radius of $1.5 \mathrm{~m}$. A belt drive, rotated by a continuously adjustable gear, induced a clockwise flow. Three flow scenarios (sub-critical (SBC), near-critical (NC) and super-critical (SPC)) were defined for the experiment based on the size-specific critical swimming speed (i.e. maximum sustainable water velocity) 
defined for early stages of this species by Flore et al. (2001). Flow velocities within the three flow scenarios, affecting the swimming speed of nase carp larvae, ranged from 0 up to $0.40 \mathrm{~m} \mathrm{~s}^{-1}$. Extruded polystyrol was used as wall material. Water depth was constant at $0.20 \mathrm{~m}$ within the main channel (Fig. 1). The inner channel (opposite to the belt drive) plus the inner part of the two circular bends were slanted at a slope of 1:2.5 towards the inner shore. This asymmetric, trapezoidal cross-section provided a heterogeneous flow pattern similar to natural riverine inshore areas. A high flow velocity gradient enabled the investigation of behavioural aspects of larval fish movement in relation to stream flow (rheoreaction).

Acoustic Doppler Velocimeter (ADV, Nortec AS Vectrino 3D Downlooking®) measurements were taken for 18 cross-sections (65 to 90 measurement points per section, 1456 points in total) at a $50 \mathrm{~Hz}$ sampling rate. The distribution of measurement points within a cross-section was based on an equidistant grid with a denser vertical grid interval in the bottom row. Water was seeded with particles during the ADV measurements to enable reliable correlation values and Signal to Strength Ratio values (SNR). These were $84 \%$ and $18 \mathrm{~dB}$ respectively and, thus, higher than the manufacturer's criteria $(75 \%$ and $15 \mathrm{~dB})$. Specific details on ADV measurements are published in (Farhadi A., Sindelar C., Tritthart M., Glas M., Blanckaert K. and Habersack H. An investigation on the outer bank cell of secondary flow in channel bends. J. Hydro-environ. Res., submitted).

\section{Numerical experiments}

Within this study, different types of numerical models were combined. First, a 3D hydrodynamic model was used to calculate steady-state flow fields, based on a computational grid in combination with a Digital Elevation Model, representative for the racetrack flume geometry. These steady-state 
flow fields were used as an input for both a numerical particle tracing and a biased and correlated random walk model $(B C R W)$ to evaluate the distribution of virtual particles and fish larvae over time. The model for the latter was altered to represent rheoreaction (RCRW).

3D hydrodynamic model

A 3D hydrodynamic model RSim-3D (Tritthart 2005), based on a finite volume approach, was applied in the flume experiment. It iteratively solved the ReynoldsAveraged Navier Stokes Equation. Turbulence closure was provided by a k- $\varepsilon$ model. The 3D hydrodynamic model is described in detail in Tritthart and Gutknecht (2007). For this model, an unstructured and polyhedral computational mesh was created, with an average distance of $0.05 \mathrm{~m}$ parallel to, and $0.025 \mathrm{~m}$ perpendicular to the outer wall. Local refinement zones along the outer wall $(10 \mathrm{~cm}$ width) were characterized by a mesh distance of up to $0.005 \mathrm{~m}$ perpendicular to the outer wall. Vertically, the mesh was divided in 8 equally distributed layers, totalling 175856 grid cells. For near wall cells, the model assumes a logarithmic velocity profile. A Digital Elevation Model (grid width: $0.01 \times 0.01 \mathrm{~m}$ ), based on geodetic levelling in combination with scale measurements, was coupled with the computational mesh. Flow was induced in the model by setting initial constant flow velocities $(S B C, N C$, $S P C)$ at points of the computational mesh, within the volume traversed by the belt drive shovels. During validation of the 3D hydrodynamic model, these initial constant flow velocities were adjusted in combination with wall roughness parameters (absolute sand roughness $k_{s}=0.2 \mathrm{~mm}$ ).

Numerical particle tracing model (Tritthart et al. 2009) 
Numerical particle tracing-based on a random walk approach-derives mean flow velocities at the Cartesian coordinates $x, y$ and $z$ from the steady-state flow field, calculated using the 3D hydrodynamic model. In discretised notation, the path of an entirely passive virtual particle is driven by:

$$
\begin{aligned}
& x(t+\Delta t)=x(t)+\overline{\boldsymbol{u} 1}(t) \Delta t+\boldsymbol{u} \mathbf{1}^{\prime}(t) \Delta t \\
& y(t+\Delta t)=y(t)+\overline{\boldsymbol{u 2}}(t) \Delta t+\boldsymbol{u} \mathbf{2}^{\prime}(t) \Delta t \\
& z(t+\Delta t)=z(t)+\overline{\boldsymbol{u} 3}(t) \Delta t+\boldsymbol{u} \mathbf{3}^{\prime}(t) \Delta t
\end{aligned}
$$

where $\overline{u 1}, \overline{u 2}$ and $\overline{u 3}$ represent vectors of mean flow velocities along the Cartesian coordinates $x, y$, and $z$ for the actual time $t$. $\Delta t$ denotes the time step of the numerical particle tracing model. A value of $\Delta t=0.05 \mathrm{~s}(20 \mathrm{~Hz})$ is recommended (Tritthart et al. 2009; Engelhardt et al. 2004) and was employed to cover actual flow velocity fluctuations $u 1^{\prime}(t)$ and $u 2^{\prime}(t)$, calculated by:

$$
\begin{aligned}
& \boldsymbol{u} \boldsymbol{1}^{\prime}(t)=2 \cdot Z_{1} \sqrt{k} \\
& \boldsymbol{u} \boldsymbol{2}^{\prime}(t)=2 \cdot Z_{2} \sqrt{k}
\end{aligned}
$$

where $Z_{1}$ and $Z_{2}$ stand for equally distributed random numbers ranging between -1 and 1 , and $k$ represents turbulent kinetic energy, a flow property derived from the Reynolds-Averaged Navier Stokes Equation of the 3D hydrodynamic model. Vertical velocity fluctuations $\mathbf{u} \mathbf{3}^{\prime}(t)$ in the direction of $z$ were not considered.

\section{Biased and correlated random walk (BCRW) model (Codling 2004)}

Codling (2004) introduced a BCRW model for the movement and navigation of fish larvae toward a reef. A Poisson distribution $\left(1 / \tau_{s} \sim \mathrm{P}(\lambda), 1 / \tau_{s} \in Z^{+}\right)$regulates the frequency of changing movement directions, where $\tau_{s}$ represents the instantaneous 
time period between direction changes. Mean time period between direction changes is defined as $\overline{\tau_{s}}=1 / \lambda$, while movement direction $\theta$ for the actual time $t$ is generated from a von Mises distribution (Batschelet 1981; Mardia \& Jupp 1999):

$T\left(\theta, \theta^{\prime}\right)=\frac{1}{2 \pi \cdot I_{0}(\kappa)} \exp \left[\kappa \cos \left(\theta-\theta^{\prime}-\mu_{\delta}\right)\right]$

where the turn angle $\delta$-the difference between the actual movement direction $\theta$ and the previous one $\theta^{\prime}$ at time $t-\tau_{\mathrm{s}}$-is defined as $\delta=\left(\theta-\theta^{\prime}\right)$, and is representative for the persistence in movement direction. The concentration parameter $\kappa$ of the von Mises distribution, dependent on the modified Bessel functions $I_{0}(\kappa)$ and denoted as 'orientating ability', determines randomness of movement direction. Mean turn angle $\mu_{\delta}$ is based on linear re-orientation (Hill and Häder 1997):

$\mu_{\delta}=d_{\tau}\left(\theta-\theta_{0}\right)$

where $d_{\tau}$ represents the amplitude of the mean turn angle, denoted as 'sensing ability', and $\theta_{0}$ the preferred movement direction. Mean re-orientation time $\bar{B}$ (s) is defined as

$\bar{B}=\frac{1}{d_{\tau} \cdot \lambda}$

and represents the dependency of the model parameters $\lambda$ and $d_{\tau}$. As a consequence, if $\lambda$ is changed, $d \tau$ needs to be adapted accordingly, if an equal sensing ability is intended.

\section{Larval fish experiments}

A total of 24 adult nase carp (Chondrostoma nasus (Linnaeus 1758)) from the River Schwechat, a tributary of the River Danube, in Austria, were hand-stripped and returned to the river. After fertilization, the nase carp larvae were laboratory-reared at 
the Department of Limnology, University of Vienna, Austria. The acquisition process is discussed in Lechner (2014b) and Zens et al. (this issue). Larvae were individually released at one of the two release sites in the flume (inshore, slow release: L; offshore, fast release: $F$ ), at one of the three flow scenarios (sub-critical: SBC; nearcritical: NC; super-critical: SPC), and at one of the diel states (day: d; night: $n$ ). A summary of the experiments is shown in Table 1. Larvae were acclimatised for one minute to flume water temperatures $\left(13.9 \pm 1.8^{\circ} \mathrm{C}\right)$ prior to each experiment. Each larva was tracked continuously for 300 seconds and recorded on a handheld video camera (Sony®, HDR-CX700VE). The observer was positioned along the inner shoreline, holding the camera at approximately shoulder height to derive similar observation angles. Night experiments were conducted in darkness from 20:30 to 23:45 h using the camera infrared function in combination with an additional infra-red light source (Sony®, HVL-HIRL). Observations were obscured by the belt drive at its location. No detectable (escape) reaction to the observer could be found during the experiments. During experiments, one of the three depth classes (surface, middle, bottom) was assigned (and audio-recorded by the experimenter) from changes observed in the height distributions of larvae. Following the experiments, the larvae were euthanized (overdose of tricaine methanesulfonate, Fulka Analytical@) and preserved in $4 \%$ formalin for later classification of larval developmental stage after Peňáz (1974), and for morphometric analysis. All experiments were in accord with the Canadian Council on Animal Care (CCAC, 2005) and the Austrian law of animal care BGBI. II Nr. 486/2004. A total of 110 experiments, across three larval developmental stages $(L 2, L 3, L 4)$, were carried out (Table 1$)$. Video footage was analysed using a $0.10 \times 0.10 \mathrm{~m}$ alphanumeric observation grid delineated on the base of the flume, and the traversed grid cells were used to define the raster-based 
larval trajectories. Residence times of larvae within an observation grid cell, height distribution within the water column, and larval orientation at the point of entry into a grid cell were evaluated. Recorded larval orientations were projected into an angular deviation from the flow direction. Orientation towards the flow indicated an angular deviation of $0^{\circ}$ (positive rheotaxis) and a positive angular deviation was represented as a clockwise angular deviation against the flow direction, as derived from the 3D hydrodynamic model. In addition, each of the traversed grid cells of the observation grid was aligned with local flow parameters derived from the 3D hydrodynamic model using block Kriging (Journel \& Huijbregts, 1978) with a block size equal to grid cell size. In this way, the observed vertical distribution of larval trajectories (bottom, intermediate or top layer) was also accounted for. Bottom and top layer observations were assigned to the respective flow velocity layers of the 3D hydrodynamic model. Intermediate larval trajectory heights were linked to a depth-averaged layer (based on layers two to seven of the eight modelled). In summary, these experiments were used to build a database of raster-based larval trajectories over time, and in combination with both abiotic (mean flow velocity, mean flow direction, diel pattern and release site), and biotic attributes (larval orientation and developmental stage).

\section{Raster-based analysis of movement patterns}

In accord with the movement patterns $(A u, A d, A p$ and $P)$, larval fish movement was investigated using the raster-based larval trajectories with the help of the numerical particle tracing model (Tritthart et al. 2009). The three-step, raster-based analysis detected the type of movement pattern at any traversed raster of the observation grid. Further analysis measured the durations of sequences of consecutive movement patterns.

Type of movement pattern 
In this study, a new method was developed to allocate the residence time of all observed larvae within each traversed grid cell (index $i$ ) of the raster-based larval trajectories to one of the four movement patterns $M$, in a three-step process. Details on this method are given in the Appendix.

The first step evaluated whether larvae within a certain grid cell were swimming upstream or downstream to evaluate the fraction of active upstream movement pattern $f_{U, M=A u}$ on the whole experimental time $T$ of all larvae within flow velocity classes $U$. A weighting factor $w_{i}$ dealt with lateral movement, as well as with flow directions non-orthogonal to the observation grid (see Appendix). The second step compared observed larval residence times with simulated residence times of numerical particles, when downstream movement was detected within the first step in a certain traversed grid cell $i$. A larval residence time greater than that of the numerical particle determined the fraction of active-passive movement $f_{U, M=A p}$ on the experimental time $T$ within flow velocity classes $U$. The last step aimed at separating the active downstream and passive movement patterns. If larvae were oriented with their heads downstream (negative rheotaxis), active downstream movement $f_{U, M=A d}$ was allocated. The remaining movement pattern without rheotaxis was considered as passive movement $f_{U, M=P \text {. }}$

Thus, the fraction $f_{U, M}$ indicated a probability of a movement pattern dependent on flow velocity. In addition, these $f_{U, M}$ fractions were calculated separately for larval trajectories for each factor (i.e. larval developmental stage, diel pattern and release site), to evaluate differences in movement patterns. Therefore, the $f_{U, M}$ fractions were arc-sine square root transformed (McCune \& Grace, 2002) to approximate normality, and tested for impacts of these factors (including flow velocity class) by using a generalised linear model (GLM, SPSS $尺$ ). Given that the number of traversed grid 
cells with flow velocities higher than $0.125 \mathrm{~m} \mathrm{~s}^{-1}$ were particularly low $(\mathrm{N} \leq 35$, Table 2) at night because the darkness reduced observational ability while filming, the differences between the factors: flow velocity class, larval developmental stage and diel pattern, were only tested for low flow velocity classes $\left(\leq 0.125 \mathrm{~m} \mathrm{~s}^{-1}\right)$. The effects of the two release sites and the three larval developmental stages were analysed using a generalised linear model for the factors: flow velocity class, larval developmental stage and release site. For release site $L$ (inshore release), the number of traversed grid cells was low when considering higher flow velocity classes and later larvae ( $\mathrm{N} \geq 9$, Table 2$)$, since these later larvae did not enter the main stream.

\section{Duration of movement patterns}

Having established the type of movement pattern $M$ of each traversed grid cell $i$ of the raster-based larval trajectories, consecutive sequences $j$ of identical movement patterns were identified, such that:

$T_{j}=\left\{\begin{array}{c}\sum_{i=1}^{n} T_{L, M, i} \text { if } M(t-1)=M(t) \\ \text { else } j=j+1\end{array}\right.$

Here, the residence times $T_{j}$, representing the durations of movement patterns of the traversed grid cells within those sequences $j$, were grouped according to both the movement pattern $M$ itself (based on the adaptation for a deterministic result, see Appendix) and each of the flow velocity classes $U$ occurring within a sequence $j$. For residence times $T_{j, M, U}$ within a certain flow velocity class $U$ and movement pattern $M$, log-normal distributions $\left(T_{j, M, U} \sim \log \mathrm{N}(a, b)\right)$ were fitted using the Maximum- 


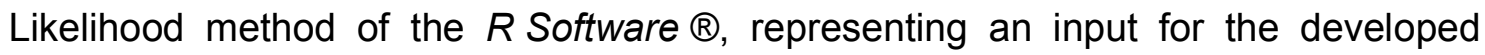
rheoreaction-based CRW model (RCRW).

\section{Rheoreaction-based CRW model (RCRW)}

Based on the findings on the type and duration of movement patterns within the racetrack flume, we developed the concept for a stage-specific and rheoreactionbased correlated and random walk (RCRW) model for nase carp larvae. The model inherits four larval movement patterns, and larval durations within these patterns, which were evaluated within the flume experiment, and it estimates these movement patterns and their durations for individual larvae over simulation time $T$. For the RCRW model, we also modified the concept of the BCRW model, developed by Codling (2004), to enable accordance with the actual movement patterns (rheoreaction). The RCRW model was coded in JAVA® as an additional tool within the software of the 3D hydrodynamic model RSim-3D (Tritthart 2005; Tritthart and Gutknecht 2007).

\section{Movement pattern}

Firstly, the model assigns a certain type of movement pattern based on the magnitude of local mean flow velocity $|\overline{\boldsymbol{U}}|(t)$ (computed a priori) within the 3D hydrodynamic model release site, and the larval developmental stage. A movement pattern at actual time $t$ is generated from the cumulative frequency distribution $F_{U, M}$, with the aid of the rejection method (Press et al. 1996), a technique to generate random numbers from a known distribution. Secondly, a duration for this movement pattern is generated from the $\log$-normal distribution $\left(\Delta t_{j, M, U} \sim \log \mathrm{N}(a, b)\right)$ fitted to observations. Estimated parameters $a$ and $b$, representative for the mean value and the standard deviation of the log-normal distribution, depend on the local mean flow 
velocity $|\overline{\boldsymbol{U}}|(t)$ and the previously generated movement pattern. This approach allows the simulation of movement patterns over a simulation time $T$ for ontogenetic stages (e.g. larval developmental stages $L 2$ or $L 4$ ), based on the observed movement patterns and durations within the flume experiment. Therefore, a cumulative frequency distribution $F_{U, M}$ and parameters $a$ and $b$ are considered model inputs (Table 5) with respect to the larval developmental stage and flow velocity class.

\section{Horizontal swimming}

For horizontal swimming, the BCRW approach according to Codling (2004) was modified with respect to movement direction $\theta$ and magnitude of swimming speed $|\boldsymbol{S}|(t)$, to account for rheoreaction over longer time periods and greater extents (10 seconds to minutes, and areas with a minimum size of grid cells $(0.10 \times 0.10 \mathrm{~m})$, respectively). Instead of the bias introduced in Codling (2004), representing navigation to a specific target (e.g. reef), here a newly developed, rheoreactive bias of movement has been implemented in the new model concept. Vertical swimming has not yet been considered. In discretised notation, the path of a virtual larvadeveloped as an extension of the numerical particle tracing model (Equation 1)—is driven by:

$$
\begin{aligned}
& x(t+\Delta t)=x(t)+\overline{\boldsymbol{u} 1}(t) \Delta t+\boldsymbol{u} \mathbf{1}^{\prime}(t) \Delta t+\boldsymbol{s} \mathbf{1}(t) \Delta t \\
& y(t+\Delta t)=y(t)+\overline{\boldsymbol{u} 2}(t) \Delta t+\boldsymbol{u} \mathbf{2}^{\prime}(t) \Delta t+\boldsymbol{s} \mathbf{2}(t) \Delta t
\end{aligned}
$$

where the added vectors $\mathbf{s} 1(t)$ and $\mathbf{s} 2(t)$ represent swimming speed in the $x$ and $y$ direction at simulation time $t$, respectively.

\section{Orientation}


The initial movement direction $\theta$ at the beginning of a movement pattern $M$ is set equal to flow direction. After each turn period $\tau_{s}$, a new movement angle $\theta$ is drawn from the von Mises distribution (Equation 3) and shifted by a turn angle $\delta$ (representative for the bias) which is derived from linear re-orientation (Equation 4). For active upstream $(A u)$ and active-passive $(A p)$ movements, the preferred movement direction $\theta_{0}$ points towards the opposite direction of local flow direction, determined by the 3D hydrodynamic model, to force movement with larvae heads pointing against flow direction. Active downstream movement (Ad) dictates a preferred direction $\theta_{0}$ towards the flow direction. Alternatively, the preferred direction can be altered by the modeller, with the angle $\theta_{c}$ representing orientation with respect to other directional cues within an inshore area (e.g. gradient of $U$, and visual cues). Thus, linear reorientation within the model is defined as:

$\mu_{\delta}=d_{\tau}\left(\theta-\theta_{0}-\theta_{C}\right)$

where positive values of $\theta_{C}$ shift the preferred direction towards the shoreline. Upon reaching a flow boundary, numerical larval trajectories are interrupted and redirected by setting the previous movement direction to a direction parallel to the boundary. Hence, resumed paths are redirected along the boundary, and multiple collisions due to correlated movement are prevented.

\section{Swimming speed}

The spatial components $\mathbf{s} 1(t)$ and $\mathbf{s} 2(t)$ of the swimming speed vector $\mathbf{S}$ at simulation time $t$ are calculated by:

$$
\mathbf{s 1}(t)=\mathbf{S}(t) \cos (\theta)
$$




$$
\boldsymbol{s} 2(t)=\mathbf{S}(t) \sin (\theta)
$$

In addition, the magnitude of the swimming speed vector $|S|(t)$-linearly dependent on the magnitude of actual mean flow velocity $|\bar{U}|(t)$, or a minimum and maximum speed $\left(S_{\min }, S_{\max }\right)$-is derived in different ways for each implemented movement pattern, except for passive movement $(|S|(t)=0)$, for each simulation time $t$ using the equation:

$$
|\boldsymbol{S}|(t)=\min \left\{\operatorname { m a x } \left\{\begin{array}{c}
\left(m(t)+R_{S}\right) R_{A p}|\overline{\boldsymbol{U}}|(t), \quad R_{A p}=1 \text { for } M \neq A p \\
S_{\text {min }} \\
S_{\max }
\end{array}\right.\right.
$$

where accordance with the actual movement pattern is determined by the Boolean function $m(t)$ ( $m=1$ : active upstream and active downstream movements, $m=0$ : active-passive movement). A higher value of $R_{S}$ corresponds to a higher swimming ability of a larva. Two options are proposed: (i) a swimming speed proportional to flow velocity $|\bar{U}|(t)$, represented by a constant factor $R_{S}$ over simulation time $T$ and, (ii) an exponentially distributed swimming speed over time related to local flow velocity $|\overline{\boldsymbol{U}}|(t)$, represented by an exponentially distributed factor $R_{S}\left(R_{S} \sim \exp (c)\right)$ generated after each turn period $\tau_{s}$. Additionally, factor $R_{A p}$ scales the swimming speed within the active-passive movement $\left(R_{A p}=1\right.$ for $\left.M \neq A p\right)$ to allow a swimming speed for this movement different from the other movement patterns. The minimum swimming speed $S_{\min }$ avoids stagnation of larvae within regions with low mean flow velocities, except for the active-passive movement, where drift rates are seen to be lower than for passive movement. The maximum swimming speed $S_{\max }$ represents an instantaneous maximum speed, not comparable with MSWV (Kaufmann 1990), 
and requires calibration, since the larval model does not account for lower flow velocities close to boundaries, due to the depth-averaged approach.

Table 5 summarises implemented model parameters and input tables, while the newly implemented model parameters require calibration during the model application, with respect to simulated and observed dispersal distances and larval residence times within the observation grid cells, when considering the two release sites $(F, L)$.

\section{Validation and sensitivity analysis}

To perform the validation and sensitivity analysis, coordinates of larval trajectories were transformed to a system with a longitudinal axis $\xi$, located at a distance of $0.25 \mathrm{~m}$ perpendicular to the outer boundary (pointing downstream) and a lateral axis $\psi(\mathrm{m})$ at the release sites (pointing to the inner shoreline). A counter for the number of traversed rounds, implemented as a real value, was calculated for each trajectory. This round number was applied as a scale for the $\xi$ axis, while the $\psi$ axis was scaled in meters. Further measures were created for the assessment of the model output. Over-re-orientation occurs when turning angles $\delta>180^{\circ}$ or $\delta<-180^{\circ}$ are generated within a time step $\tau_{s}$. Hence, the measure oRE (\%) was calculated by the durations of occurrences of over-re-orientation related to experimental time. With an error in the desired movement direction EM (\%) for each modelled movement sequence within the same movement pattern, a difference in $\xi$ between the start and endpoint of each sequence was compared to the desired movement direction of the actual movement pattern and, thus, proportions EM (\%) of sequences with wrong movement directions were calculated with respect to experimental time.

The flow field, calculated with the 3D hydrodynamic model, was depth-averaged for the RCRW model runs, since only horizontal swimming was considered. Simulated 
larvae were released at both sites $(F, L)$, according to the number of observed larvae. A stepwise increase in the number of simulated larvae (interval: 100) was analysed with a Kruskal-Wallis test $(\xi, \psi)$ for a statistically sufficient number of particles. Validation was performed by varying the model parameters until a sufficient fit of the dispersal distances $\xi$ and $\psi$, and until sufficiently small error measures $o R e$ (\%) and $E M(\%)$ were reached. Observed and simulated values of distances $\xi, \psi$ were analysed with a Mann-Whitney Rank sum test.

Sensitivity of the RCRW model regarding a change of $50 \%$ (and changes of $+100 \%$ or $+200 \%$ for $\lambda$ and $d_{\tau}$, respectively) was combined with an analysis of occurrences of over-re-orientation oRe per experimental time, as well as analysis of the proportion of wrong movement patterns EM (\%). Differences were analysed with Kruskal-Wallis tests and the Dunn's method (Post hoc test).

\section{Results}

\section{Validation of the 3D hydrodynamic model}

The 3D hydrodynamic model was validated by determining optimal values for the initial flow velocity at the site of the flume belt drive for the flow scenarios $S B C, N C$ and SPC. Here, the roughness parameter (absolute sand roughness $k_{s}$ ) was not sensitive within a range of physically realistic values. Despite small discrepancies directly beyond the site of the belt drive, due to turbulence and small waves induced by the belt drive action, the 3D hydrodynamic model was in accordance with the measurement data (Fig. 2a). The scatter plot in Figure $2 b$ underscores this finding. A Pearson product-moment correlation coefficient of $R^{2}=0.98$ for both cross-sections adjacent to the belt drive and those further away, indicates a good agreement. As a result, initial flow velocities were found to be $0.135 \mathrm{~m} \mathrm{~s}^{-1}, 0.20 \mathrm{~m} \mathrm{~s}^{-1}$ and $0.40 \mathrm{~m} \mathrm{~s}^{-1}$ for SBC, NC and SPC flow conditions, respectively. 


\section{Type of movement patterns}

The results of the three-step, raster-based analysis of movement patterns have been analysed and presented, based on the impacts of the flow velocity class, larval developmental stage, diel pattern and release site factors. In Figure 3, the frequencies of movement patterns with respect to flow velocity are separately presented for the different larval developmental stages and movement patterns.

A dominance of active movement patterns (active upstream and active-passive) was observed. For flow velocities lower than a stage-dependent swimming capacity, larvae were in the active upstream mode in the majority of cases. On the other hand, at flow velocities higher than a stage-dependent swimming capacity, larvae showed an active-downstream movement pattern.

The results of the generalised linear model, including the factors velocity class, larval developmental stage and release site, for all movement pattern fractions are summarised in Table 4. A significant goodness of fit (Omnibus test) for these applied models was reached. A significant model effect on the flow velocity factor was found for all movement patterns. Larval stage was detected as a significant model effect only for the movement patterns active upstream and passive. The release site factor predicted a significant model effect only for the active-upstream and activedownstream movements.

For the movement patterns: active-upstream, active-passive and passive, highly significant differences in means, ranging between $-14.8 \%\left(P: 0.150\right.$ to $\left.0.175 \mathrm{~ms}^{-1}\right)$ and $-67.8 \%$ ( $A u$ : 0.050 to $0.075 \mathrm{~ms}^{-1}$ ), were found for the flow velocity class factor, when compared to the highest flow velocity class $\left(0.175\right.$ to $\left.0.200 \mathrm{~ms}^{-1}\right)$. For the larval stage factor, highly significant differences in means between L2 and L4 (Au: $-13.7 \%$, $P:+12.9 \%)$ and significant differences in means between L3 and L4 (Au: $-9.0 \%, P$ : 
$+5.2 \%$ ) were found. For the movement patterns active-upstream and passive, the release site factor affected a difference in means between release site $F$ and $L$ of $7.5 \%$ and $+5.3 \%$, respectively.

The results of the applied generalised linear model concerning diel impactsincluding the flow velocity $\left(\leq 0.125 \mathrm{~m} \mathrm{~s}^{-1}\right)$ and larval developmental stage factors only-on movement patterns, indicated a small but significant difference in mean within the active downstream movement pattern (difference in means: $+3.2 \%$, $p=0.004)$. Because of the relatively small impacts of the diel factor on the type of movement patterns, and because of the low number of traversed grid cells within higher flow velocities $\left(>0.125 \mathrm{~m} \mathrm{~s}^{-1}\right)$, day and night experiments were pooled for the following analyses.

Using these results $\left(f_{U, M}\right)$ as a probability of typical movement patterns for different larval developmental stages (in particular stages $L 2$ and $L 4$ ), and for flow velocities, these patterns can be generated within the rheoreaction model with respect to release site.

\section{Durations of movement patterns}

Durations of each movement pattern $\Delta t_{j, M, U}$ were grouped for all three larval developmental stages separately, as a consequence of low numbers of sequences observed within movement patterns for specific larval stages. Table 3 lists the number of sequences within each group, separated by flow velocity class and type of movement. Groups with less than 5 sequences were not considered in this analysis. Figure 4 illustrates the measured durations of movement sequences, separated by flow velocity class and movement pattern. A decrease in durations with increasing flow velocity is noticeable. In addition, the active upstream and active-passive 
movements show the highest durations $\Delta t_{j, M, U}$. Serving as a basis for the rheoreaction-based CRW model, fitted log-normal distributions $\left(\Delta t_{j, M, U} \sim \log N(a, b)\right)$ are separately shown in Figure 5 for all flow velocity classes. The maximum likelihood estimation for fitting these log-normal distributions resulted in $P$ values significantly higher than 0.05 (ranging from 0.192 to 0.998 ). Figure 5 indicates a generally smooth transition between adjacent flow velocity classes. In general, active upstream and active-passive movements-more dependent on the behavioural aspects of larvae-show well-graded distributions, whereas passive movement, characterised by the distribution of the flow velocity field, is represented by skewed distributions with shorter durations. Thus, the results of the fitted log-normal distributions within each flow velocity class and each movement pattern are appropriate to serve as an input for the rheoreaction-based correlated random walk (RCRW) model.

\section{Rheoreaction-based correlated random walk (RCRW) model}

Taking into account the specific results of the racetrack flume experiments, the observed differences in rheoreaction of nase carp larvae between the examined flow velocity classes (representing distinct microhabitats for the larvae), as well as between larval stages $L 2$ and $L 4$ (representing the ontogenetic changes in larvae) and between inshore and offshore release sites (representing distinct hatching and/or emergence sites), a concept for a movement model within riverine inshore areas has been proposed. This new model has been validated and analysed by a sensitivity analysis for larvae of the latest developmental stage L4 within the highest flow scenario $(S P C)$. 
As a first result, a stepwise increase of the number of simulated larvae (interval: 100 larvae) indicated significant differences (Mann-Whitney Rank sum test, W=22614, $\mathrm{p}=0.51$ for 200 larvae) for $\xi$ and $\psi$ until 300 were released. Hence, a simulation with at least 300 larvae was considered sufficient, as a higher number of particles did not show any further significant differences. Further simulations inherited 1000 virtual larvae.

\section{Validation}

In order to validate the model with respect to the latest developmental stage $(L 4)$ within the highest flow scenario (SPC), a high sensing ability of $d_{\tau}=0.6$ was needed in combination with an altered preferred movement direction $\theta_{c}=45^{\circ}$ to reproduce an observed dispersal pattern. In Figure 6, it can be seen that a certain amount of observed and simulated larvae are achieving retention at the inshore area. While $49 \%$ of simulated larvae were located in the inshore area $(\psi>0.25 \mathrm{~m})$ after $100 \mathrm{~s}$, only $37.5 \%$ of larvae were released in this zone at $t=0 \mathrm{~s}$. This fraction is even larger for $t=300 \mathrm{~s}(62 \%)$, as larvae actively entered inshore areas from areas of higher flow velocity after having from zero to three rounds of the racetrack flume. While $100 \%$ of the observed larvae $(n=7)$ reached the inshore area, it is unclear if the difference in this fraction from the simulated larvae is due to the small sampling size. A Mann-Whitney Rank sum test $(U=2783, P=0.824)$ could not detect a significant difference for the lateral coordinate $\psi$ between the observed and simulated larvae after $300 \mathrm{~s}$ (Fig. 7). No significant difference was found for the longitudinal coordinate $\xi$ either $(U=21395, P=0.220)$.

Sensitivity Analysis

Overall, significant differences were found in the parameters $\xi, \psi$ and oRe for all cases of the sensitivity analysis (Kruskal-Wallis: $p<0.001$ ). Differences between 
treatments (Post hoc test: Dunn's method) are considered separately in the following.

The results of the analysis are summarized in Table 6. By varying a single model parameter, changes in the downstream and lateral dispersal parameters $\xi$ and $\psi$ were discernible, and most changes were significant (post hoc test). Also, effects on the error measures EM and oRe could be detected in the majority of cases. For example, an increase in sensing ability $d_{\tau}$ by $50 \%$ indicated a high occurrence of over-re-orientation and, thus, increased downstream displacement (median of $\xi$ : $+146 \%$ ) and reduced inshore retention (median of $\psi \cdot-87 \%$ ). Opposed to that, a decrease of $d_{\tau}$ showed an increase in the EM error by $13 \%$ in combination with a reduced inshore retention (median of $\psi \cdot-97 \%$ ).

Parameter changes indicating no significant effect on over-re-orientation and errors in the movement direction, are highlighted separately. These cases are suitable for a comparison between the different sensitivity parameters. Thereby, an increase in the parameter $R_{S}$ by $50 \%$ represents a significant downstream displacement of $48 \%$ (median) and $15 \%$ (interquartile range $(I Q R))$. Compared to that, an increase in $\kappa$ by $50 \%$ significantly reduces the median and IQR of the downstream dislocation $\xi$ by $6 \%$ and $15 \%$, respectively.

Regarding the sensitivity of $\lambda$, two cases are presented, as a consequence of the dependence of turning frequency $\lambda$ with sensing ability $d_{\tau}$ (Eq. 5). The first case, representing a decrease in rheoreaction behaviour (fixed $d_{\tau}=0.6$, variable reorientation time $B$ ), significantly increased the median of $\xi$ by $56 \%$, respectively, when $\lambda$ is increased by $100 \%$. Inshore retention is significantly decreased (median of $\psi$. $-13 \%$ ), when $\lambda$ was increased by $100 \%$. In the second case, a constant 
rheoreaction behaviour, $\left(B=0.83 \mathrm{~s}\right.$ with varying $d_{\tau}$ ), changes in the error measure EM increased by $10 \%$, when $\lambda$ was increased by $100 \%$ and, thus, a comparison of dispersal parameters $\xi$ and $\psi$ are not comparable with those of the first case of the sensitivity of $\lambda$ (decrease of rheoreaction behaviour). Finally, a sufficient number of particles within the observation grid cells was reached for all cases within the model validation and sensitivity analysis.

\section{Discussion}

In our study, movement patterns (Pavlov 1994) of nase carp larvae (Chondrostoma nasus) were evaluated within a racetrack flume, aided by a precise newly developed three-step raster-based analysis. This differs from the less-precise method of using mean swimming speeds with respect to an assumed fixed path length of $10 \mathrm{~cm}$ per grid, as carried out by Zens et al. (this issue). However, comparable fractions of larval movement were found in both studies. Comparable results of other studies are hardly available, due to spatio-temporal differences.

Within the generalised linear model, highly significant impacts on the type of movement patterns were found for the flow velocity factor. This confirms hypothesis (a): that movement patterns depend on flow velocity. In accordance with Zens et al. (this issue), we found that for higher flow conditions-corresponding to higher velocity classes in our study and higher flow scenarios in Zens et al. (this issue)active upstream movement was lower and active-passive movement was dominant. Also, in accordance with other studies (Lechner et al 2014b, Schludermann et al. 2012, Pavlov 2008), we found highly significant larval stage-specific differences ( $L 2$, L4) in the fractions of movement patterns for active upstream and passive movements. Thus hypothesis (b): that movement patterns are dependent on larval developmental stage and concomitant changes in swimming ability, is confirmed. We 
also found higher fractions of active upstream movement in $L 4$ compared to $L 2$, and of passive downstream movement in $L 2$ compared to $L 4$, in partial accordance with Zens et al. (this issue). However, Zens et al. (this issue), unlike our study, did not determine larval stage as a significant predictor for the fractions of these movement patterns. Instead, a larval stage-specific influence was found for the active-passive movement, and a further introduced downstream movement pattern, traversing. Given the wide range of flow velocities within any one of the flow scenarios ( $S B C$, $N C, S P C$ ), the results between the scenario-based approach of Zens et al. (this issue) and the flow velocity-based approach of our study are not comparable in detail.

Furthermore, we found, that offshore release reduces the fraction of the active upstream movement and increases that of the active downstream movement, when compared to inshore release. This fact confirms hypothesis (c): that larval movement patterns are dependent on the release site as an initial point, representing distinct emergence sites. Accordingly, Lechner et al. (2014b) found higher drift rates for offshore released larvae in a river with a natural gravel bar, when compared to inshore release.

Furthermore, we detected a small but significant reduction in the active downstream movement within the lower flow velocity classes $\left(U \leq 0.125 \mathrm{~m} \mathrm{~s}^{-1}\right)$ during night experiments. However, due to darkness and thus reduced observational ability while filming, within the higher flow velocity classes $U \geq 0.125 \mathrm{~m} \mathrm{~s}^{-1}$, it was not possible to test whether downstream drift was enhanced. Hence, hypothesis (d): that larval movement patterns are dependent on diel patterns characterised by a nocturnal increase in drift, could neither be sufficiently proved nor disproved in our study, 
whereas others support the concept of a diel impact on larval downstream movement (e.g. Copp et al. 2002; Zitek et al. 2004; Pavlov et al. 2008).

In light of these proven impacts on movement patterns, a stage-specific and rheoreaction-based CRW model (RCRW), using flow velocity-dependent fractions of movement patterns $f_{U, M}$, has been developed in combination with a relatively smooth transition of the fitted log-normal distributions concerning durations of movement sequences $\Delta t_{j, M, U}$ between flow velocity classes. The consideration of movement patterns and their durations, implemented as a stochastic process and derived from observed data, is the first attempt within IBM or CRW models to accurately consider data-based, spatio-temporal dispersal patterns at the micro- and meso-scales, especially in terms of the inherited combination of abiotic and biotic factors. A validation of the model with the observed larval trajectories, as suggested by Willis (2011), was applied successfully in terms of longitudinal and lateral dispersal. As model results reflect an interplay of the inherited parameters, sensitivity of the model is compounded by side effects, in terms of over-re-orientation and the desired movement pattern (reflected by the presented error measures oRe and $E M$ ). $A$ careful choice of parameters needs to be considered by the modeller. For example, the effect of turning frequency $\lambda$, considered as an independent parameter within the BCRW model (Codling 2003), could not be satisfied within the RCRW model. By changing $\lambda$ without the aim of changing re-orientation behaviour (re-orientation time $B$ defined as a constant), error measures increased. Thus, the effect of changing $\lambda$ could not be proven for the dispersal parameters $\xi$ and $\psi$ within the RCRW model. In any case, the change of orientation after each time step $\tau_{s}$ is overlaid by the change of movement patterns, defined by the log-normal distributions (durations of 
movement sequences $\left.\Delta t_{j, M, U}\right)$, since additional orientation changes were required within the model during changes of movement patterns. This modification refutes the notion that parameter $\lambda$ is insensitive and therefore should be considered within future applications of the model. For the BCRW model inheriting orientation towards a specific target, Codling (2004) presented a turning frequency $\lambda$ of $0.5 \mathrm{~Hz}$ (equal to a re-orientation time of between 4 and $20 \mathrm{~s}$ ), based on the experiments of Hill and Häder (1997). Our study proposes that much lower re-orientation times $B$ (equal to higher $\lambda$ values) are inevitable in terms of modelling rheoreaction.

Overall, the RCRW model offers the potential to investigate rheoreaction as a major cue for larvae to arrive at optimal nursery habitat conditions at riverine inshore areas and to maintain their position, or to actively or passively disperse to other suitable habitats or to the main stream. Whereas the BCRW model of Codling (2004) or Staaterman et al. (2012) only consider larvae reaching an intended target (e.g. a reef), by contrast, our RCRW model is capable of representing the context of both larval dispersal and retention processes within rivers, where hydrology and riverbed morphology strongly influence the hydraulic conditions (e.g. flow velocity, turbulence). Consequently, the spatio-temporal aspects of larval dispersal may be further examined by applying the RCRW model to various discharges, morphologies and river restoration scenarios. Thus, the model, as an integrative tool, adds to both the knowledge of spatio-temporal larval dispersal patterns, and the predictive capacity required for future river restoration projects to improve reproduction of riverine fish populations.

\section{Acknowledgements}

The authors would like to thank all who contributed to this study, especially Josef Pölzl, and Heinz Fassl and his team, from the Hydraulic Engineering Laboratory of 
the University of Natural Resources and Life Sciences, Vienna; Philipp Gmeiner from the University of Natural Resources and Life Sciences, Vienna, for his hydrodynamic pre-study and many fruitful discussions; Franz Lumesberger-Loisl and Reinhard Krusch from the University of Vienna, and Paul Humphries from Charles Sturt University, Albury, Australia. The study was financed by the Austrian Science Fund (FWF) under grant number P 22631-B17. 
1 References

2 Arnold, G. P. 1968. The orientation of plaice larvae (Pleuronectes platessa L.) in water currents. J. Exp. Bwl. 50: 785-801.

4 Armsworth, P. R. 2000. Modelling the swimming response of late stage larval reef fish to different stimuli. Mar. Ecol. Prog. Ser. 195: 231-247.

6 Atema, J., Kingsford M. J. and Gerlach G. 2002. Larval reef fish could use odour for detection, retention and orientation to reefs. Mar. Ecol. Prog. Ser. 241: 151160.

9 Batschelet, E. 1981. Circular Statistics in Biology. Academic Press 1-371.

Bearon, R. N. and Grünbaum, D. 2008. From individual behaviour to population models: A case study using swimming algae. J. Theor. Biol. 251: 679-697. doi:10.1016/j.jtbi.2008.01.007.

Béguer-Pon, M., Shan, S., Thompson, K.R., Castonguay, M., Sheng, J. and Dodson, J.J. 2015. Exploring the role of the physical marine environment in silver eel migrations using a biophysical particle tracking model. ICES J. Mar. Sci. 73(1): 57-74. doi: 10.1093/icesjms/fsv169.

Booker, D. J., Wells, N. C. and Smith, I. P. 2008. Modelling the trajectories of migrating Atlantic salmon (Salmo salar). Can. J. Fish. Aquat. Sci. 65(3): 352361.

Canadian Council on Animal Care 2005. CCAC Guidelines on: The care and use of fish in research, teaching and testing. Albert Street, Ottawa ON Canada K1P 5G4. Available from http://www.ccac.ca/Documents/Standards/Guidelines/Fish.pdf [accessed 5 May 2016]. 
25 Codling, E. A. 2003. Biased Random Walks in Biology. Doctoral Thesis, Department 26 of Applied Mathematics, The University of Leeds, Leeds.

27 Codling, E. A., Hill, N. A., Pitchford, J. W. and Simpson, S. D. 2004. Random walk 28 Ser. 279: 215-224. models for the movement and recruitment of reef fish larvae. Mar. Ecol. Prog.

Codling, E. A. and Hill, N. A. 2005. Sampling rate effects on measurements of correlated and biased random walks. J. Theor. Biol. 233: 573-588. doi:10.1016/j.jtbi.2004.11.008.

Codling, E. A., Bearon, R. N. and Thorn, G. J. 2010. Diffusion about the mean drift location in a biased random walk. Ecology 91(10): 3106-3113.

Copp, G.H., Faulkner, H., Doherty, S., Watkins, M. S. and Majecki, J. 2002. Diel drift behaviour of fish eggs and larvae, in particular barbel, Barbus barbus (L.), in an English chalk stream. Fisheries Management and Ecology 9(2): 95-103. doi: 10.1046/j.1365-2400.2002.00286.x.

Cowan, J. H., Rose K. A., Rutherford, E. S. and Houde, E. D. 1993. Individual-Based Model of Young-of-the-Year Striped Bass Population Dynamics. II. Factors Affecting Recruitment in the Potomac River, Maryland. Trans. Am. Fish. Soc. 122(3): 439-458. doi: 10.1577/15488659(1993)122<0439:IBMOYO>2.3.CO;2.

Engelhardt, C., Krüger, A., Sukhodolov, A., and Nicklisch, A. 2004. A study of phytoplankton spatial distributions, flow structure and characteristics of mixing in a river reach with groynes. J. Plankton Res. 26(11): 1351-1366.

Fisher R., Bellwood, D. R., and Job, S. D. 2000. Development of swimming abilities in reef fish larvae. Mar. Ecol. Prog. Ser. 202: 163-173.

Flore, L., Keckeis, H. and Schiemer, F. 2001. Feeding, energetic benefit and swimming capabilitiesof $0+$ nase (Chondrostoma nasus L.) in flowing water: 

an integrative laboratory approach. Large Rivers 12(2-4): 409-424. Arch. Hydrobiol. Suppl. 135(2-4): 409-424.

52 Fraenkel, G. and Gunn, D. 1940. The Orientation of Animals. Dover Publications 53 Ltd., London.

54 Gaudin, P. and Sempeski, P. 2001. The role of river bank habitat in the early life of fish: The example of grayling, Thymallus thymallus. Ecohydrology and Hydrobiology 1(1): 203-208.

Hauer, C., Unfer, G., Schmutz, S. and Habersack, H. 2008. Morphodynamic Effects

Heggenes, J. and Dokk, J. G. 2001. Contrasting temperatures, waterflows, and light: on the Habitat of Juvenile Cyprinids (Chondrostoma nasus) in a Restored

9

(1)
Austrian Lowland River. Environ. Manage. 42: 279-296.

67 Irisson, J.-O., Guigand, C. and Paris, C.B. 2009. Detection and quantification of 68 marine larvae orientation in the pelagic environment. Limnol. Oceanogr.:

\section{$69 \quad$ Methods 7: 664-672.}

70 Journel, A.G. and Huijbregts, Ch. J. 1978. Mining Geostatistics, Acad. Press, New $71 \quad$ York.

72 Johnston, T.A., Gaboury, M.N., Janusz, R.A., Janusz L.R. 1995. Larval fish drift in 73 the Valley River, Manitoba: influence of abiotic and biotic factors, and 
relationships with future year class strengths. Can J Fish Aquat Sci. 52:24232431. doi:10.1139/F95-833.

Kaufmann, R. 1990. Respiratory cost of swimming in larval and juvenile cyprinids. J. Exp. Biol. 150: 343-366.

Keckeis, H., Frankiewicz, P. and Schiemer, F. 1996. The importance of inshore areas for spawning nase Chondrostoma nasus (Cyprinidae) in a free-flowing section of a large river (Danube, Austria). Large Rivers 10: 51-64.

Kingsford, M. J., Leis, J. M., Shanks, A., Lindeman, K. C., Morgan, S. G., and Pineda J. 2002. Sensory environments, larval abilities and local self recruitment. Bull. Mar. Sci. 70(1): 309-340.

Kirchhofer, A. 1996. Fish Conservation in Switzerland - three Case Studies. In Conservation of endangered Freshwater Fish in Europe Edited by Kirchhofer A. and Hefti D. Birkhäuser Verlag, Basel, pp. 135-145

Korman, J., Wiele, S. M. and Torizzo, M. 2004. Modelling effects of discharge on habitat quality and dispersal of juvenile Humpback chub (Gila cyphia) in the Colorado River, Grand Canyon. River Res. Applic. 20: 379-400.

Lechner, A., Keckeis, H., Schludermann, E., Humphries, P., McCasker, N., and Tritthart, M. 2014a. Hydraulic forces impact larval fish drift in the free flowing section of a large European river. Ecohydrology 7: 648-658. doi: 10.1002/eco.1386.

Lechner, A., Keckeis H., Schludermann, E., Loisl, F., Humphries, P., Glas, M., Tritthart, M. and Habersack, H. 2014b. Shoreline configurations affect dispersal patterns of fish larvae in a large river. ICES J. Mar. Sci. 71(4). 930942. doi:10.1093/icesjms/fst139. 
98 Lechner, A., Keckeis, H. and Humphries, P. 2016. Patterns and processes in the drift 99 of early developmental stages of fish in rivers: a review. Rev. Fish. Biol.

100 Fisheries. Published Online 07 June 2016. doi:10.1007/s11160-016-9437-y.

101 Leis, J.M. and Carson-Ewart, B.M. 1997. In situ swimming speeds of the late pelagic 102 larvae of some Indo-Pacific coral-reef fishes. Mar. Ecol. Prog. Ser. 159: 165$103 \quad 174$.

104 Leis, J. M. 2006. Are Larvae of Demersal Fishes Plankton or Nekton? Advances in 105 marine biology 51: 58-141.

106 Leis, J. M., Paris C. B., Irisson, J.-O., Yerman, M. N. and Siebeck, U. E. 2014.

107 Orientation of fish larvae in situ is consistent among locations, years and 108 methods, but varies with time of day. Mar. Ecol. Prog. Ser. 505: 193-208. doi: $109 \quad 10.3354 /$ meps 10792.

110 Lelek, A. 1987. The freshwater fishes of Europe, Vol. 9. Threatened Fishes of $111 \quad$ Europe. Aula-Verlag, Wiesbaden

112 Le Pichon, C., Tales, É., Gorges, G., Baudry, J. and Boët, P. 2016. Using a 113 continuous riverscape survey to examine the effects of the spatial structure of 114 functional habitats on fish distribution. J. Freshwater Ecol. 31 (1): 1-19.

115 Lusk, S. and Halačaka, K. 1995. Anglers' catches as an indicator of population size 116 of the nase, Chondrostoma nasus. Folia Zool. 44: 185-192.

117 Marcos, Fu H. C., Powers, T. R. and Stocker, R. 2012. Bacterial rheotaxis. Proc.

118 Natl. Acad. Sci. USA. 109(13): 4780-4785. doi: 10.1073/pnas.1120955109.

119 Mardia, K. V. and Jupp, P. E. 1999. Directional Statistics. John Wiley \& Sons, Inc. 1120 456. 
121 Matanoski, J. C. and Hood, R. R. 2006. An individual-based numerical model of

122 medusa swimming behaviour. Marine Biology 149: 595-608. doi:

$123 \quad 10.1007 / \mathrm{s} 00227-006-0244-1$.

124 McCune, B. and Grace, J. B. 2002. Analysis of Ecological Communities. MjM

125 Software Design.

126 Miller, T. 2007. Contribution of individual-based coupled physical: biological models

127 to understanding recruitment in marine fish populations. Mar. Ecol. Prog. Ser.

$128 \quad 347:$ 127-138. doi: 10.3354/meps06973.

129 Mork, K. A., Gibley, J., Hansen, L. P., Jensen, A. J., Jacobsen, J. A., Holm, M.,

130 Holst, J. C., Maoiléidigh, N. Ó., Vikebø, F., McGinnity, P., Melle, W., Thomas,

131 K., Verspoor, E. and Wennevik, V. 2012. Modelling the migration of post smolt

132 Atlantic Salmon (Salmo salar) in the Northeast Atlantic. ICES J. Mar. Sci.

69(9); 1616-1624. doi:10.1093/icesjms/fss108.

134 Paris, C. B., Chérubin, L. M., and Cowen, R. K. 2007. Surfing, spinning, or diving

135 from reef to reef: Effects on population connectivity. Mar. Ecol. Prog. Ser. 347:

$136 \quad$ 285-300. doi:10.3354/meps06985

137 Paris, C. B., Helgers J., van Sebille, E. and Srinivasan, A. 2013. Connectivity

138 Modeling System: A probabilistic modelling tool for the multi-scale tracking of

139 biotic and abiotic variability in the ocean. Environmental Modelling \& Software

$140 \quad$ 42: $47-54$.

141 Pavlov, D. S. 1994. The downstream migration of young fishes in rivers:

142 mechanisms and distribution. Folia Zoologica 43: 193-208.

143 Pavlov, D. S., Mikheev, V. N., Lupandin, A. I., and Skorobogatov, M. A. 2008.

144 Ecological and behavioural influences on juvenile fish migrations in regulated 
rivers: a review of experimental and field studies. Hydrobiologia 609:125-138. doi:10.1007/s10750-008-9396-y.

Pavlov, D.S., Kostin, V.V., Zvezdin, A.O. and Ponomareva, V.Y. 2010. On methods

Peňáz, M. 1974. Early development of the nase carp, Chondrostoma nasus (Linnaeus, 1758). Zoologické Listy 23 (3), 275-288.

Peňáz, M., Baruš, V. and Prokeš, M. 1996. Fish assemblage structure in a reservoir

Press, W.H., Teukolsky, S.A., Vetterling, W.T. and Flannery, B.P., 1996. Numerical with an extreme hydrological regime (Mohelno Reservoir, Czech Republic). recipes in $\mathrm{C}$ (Vol. 2). Cambridge: Cambridge university press.

Reichard, M., Jurajda, P. and Ondračkovaá, M. 2002, Interannual variability in seasonal dynamics and species composition of drifting young-of-the-year fishes in two European lowland rivers. Journal of Fish Biology, 60: 87-101. doi:10.1111/j.1095-8649.2002.tb02389.x.

Reichard, M. and Jurajda, P. 2004. The effects of elevated river discharge on the downstream drift of young-of-the-year cyprinid fishes. J. Freshwater Ecol. 19(3): 465-471.

Schludermann, E., Tritthart, M., Humphries, P. and Keckeis, H. 2012. Larval dispersal and settlement of fish larvae in a large temperate river: an experimental study. Can. J. Fish. Aquat. Sci. 69: 1302-1315. 
170 Staaterman, E., Paris, C. B. and Helgers, J. 2012. Orientation behaviour in fish

171 larvae: A missing piece to Hjort's critical period hypothesis. Journal of

172 Theoretical Biology, 304: 188-196. doi: 10.1016/j.jtbi.2012.03.016.

173 Stobutzki, I.C. and Bellwood, D.R. 1994. An analysis of the sustained swimming 174 abilities of pre- and post-settlement coral reef fishes. J. Exp. Mar. Biol. Ecol. 175 (2): 275-286. doi: 10.1016/0022-0981(94)90031-0.

176 Tritthart, M. 2005. Three-Dimensional Numerical Modelling of Turbulent River Flow 177 using Polyhedral Finite Volumes. Wiener Mitteilungen, Wasser-Abwasser$178 \quad$ Gewässer, Band 193: 1-179.

179 Tritthart, M. and Gutknecht, D. 2007. Three-dimensional simulation of free-surface 180 flows using polyhedral finite volumes. Engineering Applications of $181 \quad$ Computational Fluid Mechanics. 1: 1-14.

182 Tritthart, M., Liedermann, M. and Habersack, H. 2009. Modelling spatio-temporal 183 flow characteristics in groyne fields. River Research and Applications. 25: 62$184 \quad 81$.

185 Vikebø, F., Jørgensen, C., Kristiansen, T. and Fiksen, Ø. 2007. Drift, growth and 186 survival of larval Northeast Arctic cod with simple rules of behavior. Mar. Ecol. 187 Prog. Ser. 347: 207-219. doi: 10.3354/meps06979.

188 Werner, F. E., Page, F. H., Lynch, D. R., Loder, J. W., Lough, R. G., Perry R. I., 189 Greenberg, D. A. and Sinclair, M. M. 1993. Influences of mean advection and 190 simple behaviour on the distribution of cod and haddock early life stages on 191 Georges Bank. Fish. Oceanogr. 2(2): 43-64.

192 Werner, F. E., MacKenzie, B.R., Perry R. I., Lough, R.G., Naimie, C.E., Blanton, 193 B.O. and Quinlan, J.A. 2001(a). Larval trophodynamics, turbulence and drift 
on Georges Bank: a sensitivity analysis of cod and haddock. Scientia Marina 65(Suppl. 1): 99-115.

Werner, F. E., Quinlan, J., Lough, R. and Lynch, D. 2001(b). Spatially-explicit individual based modelling of marine populations: a review of the advances in the 1990s. Sarsia 86: 411-421.

Willis, J. 2011. Modelling swimming aquatic animals in hydrodynamic models. Ecological Modelling 222: 3869-3887.

201 Wolter, C. and Sukhodolov, A. 2008. Random displacement versus habitat choice of 202 fish larvae in rivers. River. Res. Applic. 24: 661-672. doi: 10.1002/rra.1146.

203 Zitek, A., Schmutz, S. and Ploner, A. 2004. Fish drift in a Danube sidearm-system: II. 204 Seasonal and diurnal patterns. J. Fish Biol. 65(5): 1339-1357. doi: 10.1111/j.1095-8649.2004.00534.x. 
Tables

207 Table 1: Summary of experiments for larval developmental stages $(L 2, L 3$ and $L 4)$ separated by: diel pattern $(d, n)$, release site $(F$,

$208 L)$ and flow scenario $(S B C, N C, S P C)$, as well as statistics of the total larval lengths and MSWV for larval developmental stages.

\begin{tabular}{|c|c|c|c|c|c|c|c|c|c|c|c|c|c|c|c|c|}
\hline \multirow[t]{4}{*}{ stage } & \multicolumn{13}{|c|}{ number of experiments } & \multicolumn{2}{|c|}{$\mathrm{TL}^{*}$} & \multirow{4}{*}{$\begin{array}{l}M S W V+ \\
\left(\mathrm{cm} \mathrm{s}^{-1}\right)\end{array}$} \\
\hline & \multicolumn{6}{|c|}{$d$ (day) } & \multicolumn{6}{|c|}{$n$ (night) } & \multirow[t]{3}{*}{ total } & \multirow{3}{*}{$\begin{array}{l}\text { mean } \\
(\mathrm{mm})\end{array}$} & \multirow{3}{*}{$\begin{array}{r}\mathrm{SD} \\
(\mathrm{mm}) \\
\end{array}$} & \\
\hline & \multicolumn{3}{|c|}{$F$ (offshore) } & \multicolumn{3}{|c|}{$L$ (inshore) } & \multicolumn{3}{|c|}{$F$ (offshore) } & \multicolumn{3}{|c|}{$L$ (inshore) } & & & & \\
\hline & $S B C$ & NC & $S P C$ & $S B C$ & $N C$ & $S P C$ & $S B C$ & $N C$ & $S P C$ & $S B C$ & $N C$ & $S P C$ & & & & \\
\hline L2 & 5 & 5 & 3 & 4 & 4 & 2 & 5 & 3 & 0 & 3 & 3 & 0 & 37 & 12.95 & 0.50 & 10.3 \\
\hline L3 & 2 & 4 & 4 & 5 & 4 & 7 & 4 & 2 & 0 & 4 & 3 & 2 & 41 & 14.36 & 0.82 & 10.9 \\
\hline L4 & 4 & 3 & 4 & 1 & 3 & 2 & 1 & 5 & 0 & 5 & 3 & 1 & 32 & 16.19 & 0.63 & 11.8 \\
\hline
\end{tabular}

209 *total length of larva

210 † maximum sustainable water velocity after Kaufmann (1990) 
211 Table 2: Numbers of traversed observation grid cells $i$ separated by flow velocity class, larval developmental stage ( $L 2, L 3, L 4)$, diel

212 pattern $(d, n)$ and release site $(F, L)$

\begin{tabular}{|c|c|c|c|c|c|c|c|c|c|c|c|c|c|c|c|}
\hline \multirow{3}{*}{$\begin{array}{l}\text { flow velocity } \\
\text { class }\left(\mathrm{m} \mathrm{s}^{-1}\right)\end{array}$} & \multicolumn{3}{|c|}{ total } & \multicolumn{3}{|c|}{ day } & \multicolumn{3}{|c|}{ night } & \multicolumn{3}{|c|}{ fast release } & \multicolumn{3}{|c|}{ slow release } \\
\hline & \multicolumn{3}{|c|}{ stage } & \multicolumn{3}{|c|}{ stage } & \multicolumn{3}{|c|}{ stage } & \multicolumn{3}{|c|}{ stage } & \multicolumn{3}{|c|}{ stage } \\
\hline & $\angle 2$ & $L 3$ & $L 4$ & $L 2$ & $L 3$ & $\llcorner 4$ & $\angle 2$ & $L 3$ & $\angle 4$ & $\angle 2$ & $L 3$ & $\angle 4$ & $\angle 2$ & $L 3$ & $\angle 4$ \\
\hline $0.000-0.025$ & 367 & 218 & 151 & 155 & 88 & 42 & 212 & 130 & 109 & 229 & 65 & 38 & 138 & 153 & 113 \\
\hline $0.025-0.050$ & 434 & 457 & 243 & 263 & 286 & 110 & 171 & 171 & 133 & 228 & 142 & 95 & 206 & 315 & 148 \\
\hline $0.050-0.075$ & 584 & 493 & 372 & 429 & 319 & 230 & 155 & 174 & 142 & 327 & 172 & 162 & 257 & 321 & 210 \\
\hline $0.075-0.100$ & 510 & 585 & 584 & 399 & 394 & 282 & 111 & 191 & 302 & 300 & 262 & 307 & 210 & 323 & 277 \\
\hline $0.100-0.125$ & 258 & 260 & 281 & 179 & 225 & 183 & 79 & 35 & 98 & 179 & 130 & 190 & 79 & 130 & 91 \\
\hline $0.125-0.150$ & 68 & 79 & 66 & 54 & 78 & 38 & 14 & 1 & 28 & 39 & 28 & 58 & 29 & 51 & 8 \\
\hline $0.150-0.175$ & 133 & 128 & 124 & 133 & 125 & 120 & 0 & 3 & 4 & 65 & 52 & 89 & 68 & 76 & 35 \\
\hline $0.175-0.200$ & 169 & 108 & 84 & 169 & 104 & 84 & 0 & 4 & 0 & 116 & 49 & 75 & 53 & 59 & 9 \\
\hline $0.200-0.225$ & 118 & 98 & 48 & 118 & 98 & 48 & 0 & 0 & 0 & 61 & 66 & 38 & 57 & 32 & 10 \\
\hline
\end{tabular}


214 Table 3: Numbers of sequences $j$ including consecutive traversed grid cells $i$ within 215 the same movement patterns. Instances with less than 5 sequences were not 216 considered for the analysis of the durations of movement patterns.

\begin{tabular}{lrrrr}
\hline \multirow{2}{*}{$\begin{array}{l}\text { flow velocity } \\
\text { class }\left(\mathrm{m} \mathrm{s}^{-1}\right)\end{array}$} & \multicolumn{4}{c}{ type of movement pattern } \\
\cline { 2 - 5 } & $A u$ & $A d$ & $A p$ & $P$ \\
\hline $0.000-0.025$ & 91 & 33 & 75 & 33 \\
$0.025-0.050$ & 164 & 26 & 149 & 31 \\
$0.050-0.075$ & 218 & 16 & 214 & 47 \\
$0.075-0.100$ & 204 & 23 & 253 & 68 \\
$0.100-0.125$ & 86 & 7 & 136 & 39 \\
$0.125-0.150$ & 18 & 8 & 49 & 16 \\
$0.150-0.175$ & 5 & 3 & 68 & 51 \\
$0.175-0.200$ & 4 & 10 & 71 & 51 \\
$0.200-0.225$ & 0 & 8 & 56 & 45 \\
\hline
\end{tabular}

217 
218 Table 4: Result of the GLM per movement pattern for factors flow velocity class, larval developmental stage and release site.

219 Significant changes are marked in bold.

\begin{tabular}{|c|c|c|c|c|c|c|c|c|c|c|c|c|}
\hline & & \multicolumn{2}{|c|}{ active upstream, $A u$} & \multicolumn{3}{|c|}{ active downstream, Ad } & \multicolumn{3}{|c|}{ active-passive, $A p$} & \multicolumn{3}{|c|}{ passive, $P$} \\
\hline \multirow{2}{*}{\multicolumn{2}{|c|}{ omnibus test }} & $\chi^{2 *} \mathrm{df}$ & $p$ & $\chi^{2 *}$ & df & $p$ & $\chi^{2 *}$ & df & $\mathrm{p}$ & $\chi^{2 *}$ & df & $\mathrm{p}$ \\
\hline & & $74.440 \quad 11$ & $<0.001$ & 23.057 & 11 & 0.017 & 95.265 & 11 & $<0.001$ & 86.942 & 11 & $<0.001$ \\
\hline \multirow{5}{*}{$\begin{array}{l}\text { test of model } \\
\text { effects }\end{array}$} & factor & $\chi^{2} \dagger$ & $\mathrm{p}$ & $\chi^{2} \dagger$ & df & $\mathrm{p}$ & $\chi^{2} \dagger$ & df & $\mathrm{p}$ & $\chi^{2} \dagger$ & df & $\mathrm{p}$ \\
\hline & constant & 1469.8 & $<0.001$ & 94.2 & 1 & $<0.001$ & 3525.69 & 1 & $<0.001$ & 613.521 & 1 & $<0.001$ \\
\hline & flow velocity class & 245.86 & $<0.001$ & 21.91 & 8 & 0.005 & 157.593 & 8 & $<0.001$ & 180.126 & 8 & $<0.001$ \\
\hline & larval stage & 10.736 & 0.005 & 2.16 & 2 & 0.340 & 1.869 & 2 & 0.393 & 33.987 & 2 & $<0.001$ \\
\hline & release site & 4.583 & 0.032 & 4.69 & 1 & 0.030 & 0.866 & 1 & 0.352 & 2.047 & 1 & 0.153 \\
\hline \multirow{15}{*}{$\begin{array}{l}\text { difference in } \\
\text { means }\end{array}$} & flow velocity class $\ddagger$ & $\Delta \S$ & $p$ & $\Delta \S$ & & $p$ & $\Delta \S$ & & $p$ & $\Delta \S$ & & $p$ \\
\hline & 0.000 to 0.025 & 0.6525 & $<0.001$ & 0.0494 & & 0.343 & -0.3735 & & $<0.001$ & -0.2841 & & $<0.001$ \\
\hline & 0.025 to 0.050 & 0.6776 & $<0.001$ & -0.0618 & & 0.236 & -0.3378 & & $<0.001$ & -0.3448 & & $<0.001$ \\
\hline & 0.050 to 0.075 & 0.7134 & $<0.001$ & -0.1213 & & 0.020 & -0.3566 & & $<0.001$ & -0.3452 & & $<0.001$ \\
\hline & 0.075 to 0.100 & 0.6667 & $<0.001$ & -0.0981 & & 0.060 & -0.3187 & & $<0.001$ & -0.3379 & & $<0.001$ \\
\hline & 0.100 to 0.125 & 0.6083 & $<0.001$ & -0.1187 & & 0.023 & -0.2567 & & $<0.001$ & -0.3496 & & $<0.001$ \\
\hline & 0.125 to 0.150 & 0.4140 & $<0.001$ & -0.0410 & & 0.432 & -0.1588 & & 0.004 & -0.2543 & & $<0.001$ \\
\hline & 0.150 to 0.175 & 0.1942 & 0.008 & -0.1245 & & 0.017 & 0.0091 & & 0.869 & -0.1481 & & $<0.001$ \\
\hline & 0.175 to 0.200 & 0.0462 & 0.530 & -0.0282 & & 0.588 & 0.0603 & & 0.278 & -0.0920 & & 0.017 \\
\hline & larval stage & $\Delta \S$ & $p$ & $\Delta \S$ & & $\mathrm{p}$ & $\Delta \S$ & & $p$ & $\Delta \S$ & & $\mathrm{p}$ \\
\hline & L2 to L3 & -0.0464 & 0.274 & 0.0266 & & 0.377 & -0.0212 & & 0.510 & 0.0766 & & $<0.001$ \\
\hline & $\mathrm{L} 2$ to $\mathrm{L} 4$ & -0.1369 & $<0.001$ & 0.0439 & & 0.145 & 0.0227 & & 0.479 & 0.1289 & & $<0.001$ \\
\hline & $\mathrm{L} 3$ to $\mathrm{L} 4$ & -0.0904 & 0.033 & 0.0173 & & 0.565 & 0.0439 & & 0.172 & 0.0523 & & 0.019 \\
\hline & release site & $\Delta \S$ & $\mathrm{p}$ & $\Delta \S$ & & $\mathrm{p}$ & $\Delta \S$ & & $\mathrm{p}$ & $\Delta \S$ & & $\mathrm{p}$ \\
\hline & $\mathrm{F}$ to $\mathrm{L}$ & -0.0743 & 0.032 & 0.0532 & & 0.030 & 0.0244 & & 0.352 & 0.0260 & & 0.153 \\
\hline
\end{tabular}


$220 *$ * likelihood quotient of the omnibus test

$221+$ Wald $\chi^{2}$

$222 \ddagger$ difference in means versus flow velocity class 0.200 to 0.225

223 § mean difference 
224 Table 5: Input values or tables, model parameters and typical values used in the

225 literature

\begin{tabular}{|c|c|c|c|}
\hline $\begin{array}{l}\text { Input value, } \\
\text { table or } \\
\text { parameter }\end{array}$ & Description & Typical values* & Reference \\
\hline$x(t=0), y(t=0)$ & release site $(\mathrm{m})$ & $\begin{array}{l}\text { inshore } L \text {, offshore } \\
F\end{array}$ & this paper \\
\hline$F_{U, M}$ & $\begin{array}{l}\text { input table for cumulative } \\
\text { frequencies with respect to flow } \\
\text { velocity class } U \text {, type of movement } \\
\text { pattern } M \text { and release site }\end{array}$ & - & this paper \\
\hline$a, b$ & $\begin{array}{l}\text { input table for parameters of the } \\
\text { log-normal distributed durations of } \\
\text { movement sequences with respect } \\
\text { to flow velocity class } U \text { and type of } \\
\text { movement pattern } M\end{array}$ & - & this paper \\
\hline$\Delta t$ & time step of discretisation (s) & $0.05 \mathrm{~s}$ & Tritthart et al. (2009) \\
\hline$T$ & simulation time (s) & $300 \mathrm{~s}$ & this paper \\
\hline$\lambda$ & turning frequency $(\mathrm{Hz})$ & $\begin{array}{l}0.5 \mathrm{~Hz} \\
2 \mathrm{~Hz}, 3 \mathrm{~Hz}, 4 \mathrm{~Hz}\end{array}$ & $\begin{array}{l}\text { Codling (2004) } \\
\text { this paper }\end{array}$ \\
\hline$\left(\Delta t_{s}\right)$ & fixed time step $\Delta t_{s}$ for turns (s) & $6 \mathrm{~min}, 30 \mathrm{~min}, 1 \mathrm{~h}$ & Staaterman (2012) \\
\hline$\kappa$ & orientating ability & $0.2,1,2,4$ & Codling (2004) \\
\hline$d_{\tau}$ & sensing ability & $\begin{array}{l}2.5,4.5 \\
0.1,0.3,0.5,1\end{array}$ & $\begin{array}{l}\text { Staaterman (2012) } \\
\text { Codling (2004) }\end{array}$ \\
\hline$\theta_{C}$ & $\begin{array}{l}\text { altered preferred direction with } \\
\text { respect to cues other than } \\
\text { rheoreaction }\left(^{\circ}\right)\end{array}$ & - & - \\
\hline$R_{S}$ & $\begin{array}{l}\text { scale factor for swimming speed, } \\
\text { constant or exponentially } \\
\text { distributed: }\end{array}$ & - & - \\
\hline$c$ & $\mathrm{R}_{\mathrm{S}} \sim \exp (c)$ & & \\
\hline $\mathrm{R}_{\mathrm{Ap}}$ & $\begin{array}{l}\text { additional scale factor for } \\
\text { swimming speed for movement } \\
\text { pattern } A p\end{array}$ & - & - \\
\hline$S_{\min }$ & minimum swimming speed $\left(\mathrm{m} \mathrm{s}^{-1}\right)$ & - & - \\
\hline$S_{\max }$ & maximum swimming speed $\left(\mathrm{m} \mathrm{s}^{-1}\right)$ & - & - \\
\hline
\end{tabular}

226 *If typical values are not proposed, the parameter or input table is a calibration

227 parameter of the developed rheoreaction model RCRW 
228 Table 6: Result of the sensitivity analysis for selected parameters of the RCRW model regarding the transformed longitudinal and 229 lateral coordinates $\xi$ and $\psi$, in combination with the error measures $o R e$ and $E M$. Significant changes in combination with low error 230 measures oRe and EM are marked bold.

\begin{tabular}{|c|c|c|c|c|c|c|c|c|c|c|c|c|c|c|c|}
\hline \multicolumn{3}{|l|}{ Parameter } & \multicolumn{5}{|c|}{$\xi$ (rounds) } & \multicolumn{5}{|c|}{$\psi(m)$} & \multirow{2}{*}{$\frac{\text { oRe (\%) }}{\text { Median }}$} & \multicolumn{2}{|c|}{$E M(\%)$} \\
\hline & & $\Delta(\%)$ & Median & $\Delta(\%)$ & $I Q R$ & $\Delta(\%)$ & Sig. * & Median & $\Delta(\%)$ & $I Q R$ & $\Delta(\%)$ & Sig. * & & & $\Delta(\%)$ \\
\hline \multirow[t]{2}{*}{$\mathrm{d}_{\tau}$} & 0.3 & -50 & 1.00 & -7 & 0.46 & -62 & $p<0.05$ & 0.01 & -97 & 0.81 & +29 & $p<0.05$ & 0.0 & 31 & +13 \\
\hline & 0.6 & & 1.08 & & 1.20 & & & 0.49 & & 0.63 & & & 0.1 & 18 & \\
\hline \multicolumn{16}{|l|}{$\lambda(d \tau=0.6)$} \\
\hline$B=0.83 \mathrm{~s}$ & 2 & & 1.08 & & 1.201 & & & 0.49 & & 0.6 & & & 0.1 & 18 & \\
\hline$B=0.56 \mathrm{~s}$ & 3 & +50 & 1.47 & +37 & 1.247 & +4 & $p<0.05$ & 0.48 & -2 & 0.6 & -3 & & 1.1 & 12 & -6 \\
\hline$B=0.42 \mathrm{~s}$ & 4 & +100 & 1.68 & +56 & 1.433 & +19 & $p<0.05$ & 0.43 & -13 & 0.6 & -1 & $p<0.05$ & 1.1 & 17 & -1 \\
\hline \multicolumn{16}{|c|}{$\lambda(B=0.83 \mathrm{~s}) \dagger$} \\
\hline$d \tau=0.60$ & 2 & & 1.08 & & 1.201 & & & 0.49 & & 0.6 & & & 0.1 & 18 & \\
\hline$d \tau=0.40$ & 3 & +50 & 0.97 & -10 & 0.5 & -58 & $p<0.05$ & 0.52 & +6 & 0.7 & +13 & & 0.0 & 27 & +9 \\
\hline$d \tau=0.30$ & 4 & +100 & 1.05 & -3 & 0.508 & -58 & $p<0.05$ & 0.23 & -53 & 0.9 & +41 & $p<0.05$ & 0.0 & 28 & +10 \\
\hline \multirow[t]{4}{*}{$\kappa$} & 2 & -50 & 1.85 & +72 & 1.32 & +10 & $p<0.05$ & 0.37 & -24 & 0.69 & +9 & $p<0.05$ & 5.6 & 17 & -1 \\
\hline & 4 & & 1.08 & & 1.20 & & & 0.49 & 0 & 0.63 & & & 0.1 & 18 & \\
\hline & 6 & +50 & 1.01 & -6 & 1.02 & -15 & $p<0.05$ & 0.49 & 0 & 0.67 & +5 & & 0.2 & 17 & -1 \\
\hline & 12 & +200 & 0.77 & -29 & 1.01 & -16 & $p<0.05$ & 0.53 & +8 & 0.63 & 0 & & 0.0 & 18 & 0 \\
\hline \multirow{3}{*}{$\theta_{\mathrm{c}}$} & 22.5 & -50 & 1.02 & -5 & 0.91 & -25 & $p<0.05$ & 0.48 & -2 & 0.67 & +5 & & 0.3 & 18 & 0 \\
\hline & 45 & & 1.08 & & 1.20 & & & 0.49 & & 0.63 & & & 0.1 & 18 & \\
\hline & 67.5 & +50 & 1.74 & +62 & 1.38 & 15 & $p<0.05$ & 0.35 & -28 & 0.70 & +10 & $p<0.05$ & 2.8 & 18 & 0 \\
\hline \multirow[t]{3}{*}{$\mathrm{R}_{\mathrm{S}}$} & 0.1 & -50 & 2.07 & +92 & 0.68 & -43 & $p<0.05$ & -0.06 & -112 & 0.44 & -31 & $p<0.05$ & 2.9 & 17 & -1 \\
\hline & 0.2 & & 1.08 & & 1.20 & & & 0.49 & & 0.63 & & & 0.1 & 18 & \\
\hline & 0.3 & +50 & 0.21 & -81 & 1.01 & -16 & $p<0.05$ & 0.52 & +7 & 0.57 & -10 & $p<0.05$ & 0.5 & 25 & +7 \\
\hline \multirow[t]{3}{*}{$\mathrm{R}_{\mathrm{Ap}}$} & 0.1 & -50 & 0.86 & -20 & 1.58 & +32 & $p<0.05$ & 0.45 & -8 & 0.75 & +18 & & 0.8 & 14 & -4 \\
\hline & 0.2 & & 1.08 & & 1.20 & & & 0.49 & & 0.63 & & & 0.1 & 18 & \\
\hline & 0.3 & +50 & 0.56 & -48 & 1.02 & -15 & $p<0.05$ & 0.58 & +19 & 0.51 & -20 & $p<0.05$ & 0.4 & 20 & 2 \\
\hline
\end{tabular}

* Post hoc test: Dunn's method

$\dagger$ a decrease of $\lambda$ by $50 \%(\lambda=1)$ was not possible, as sensing ability $d_{\tau}$ would require a value greater than $1\left(d_{\tau}=1.34\right)$ 


\section{Figures}

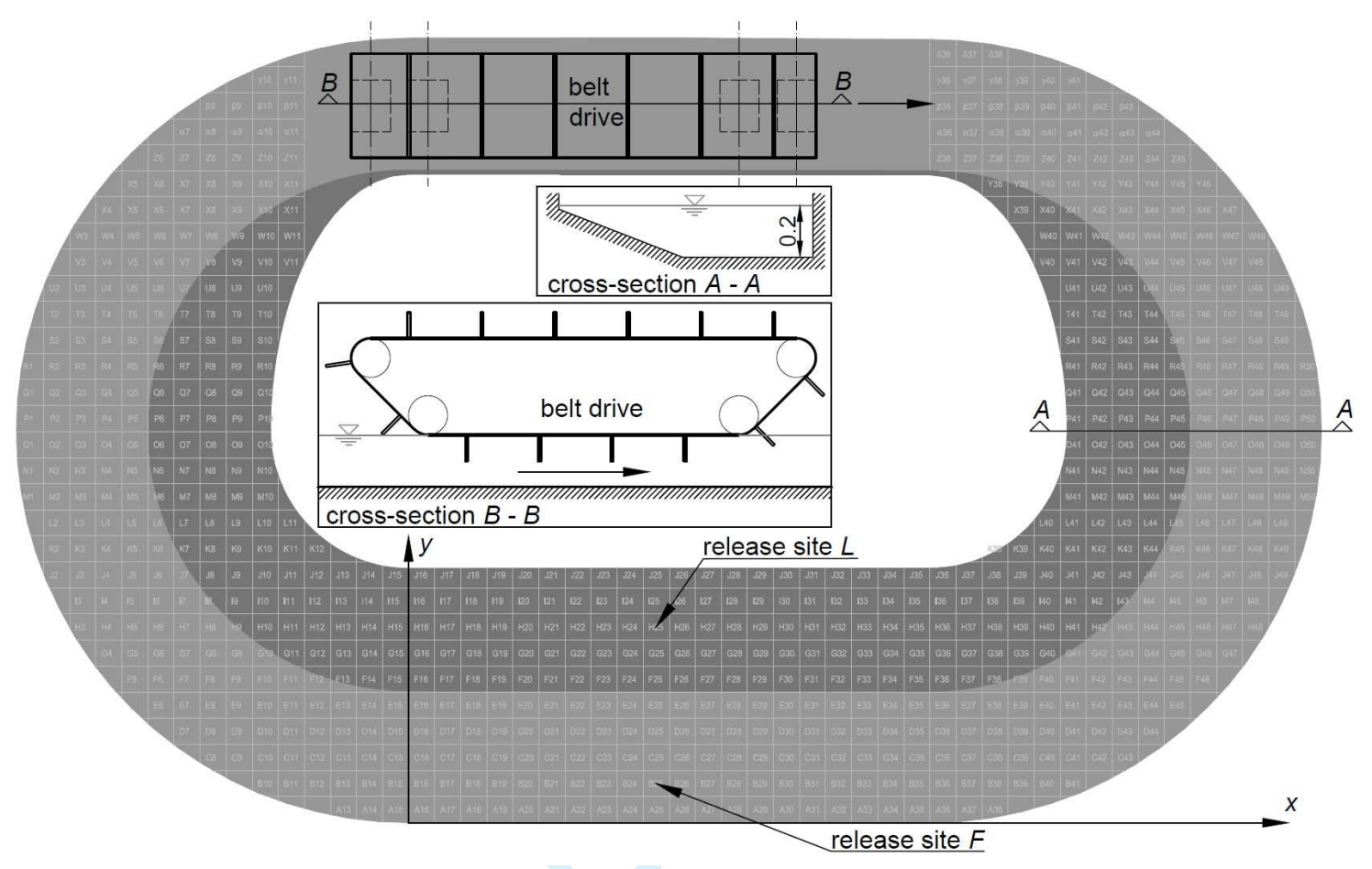

Figure 1: View from above of the racetrack flume (3 by $5 \mathrm{~m}$ in size) depicting a clockwise flow direction. The light grey-shaded area represents the main channel and dark grey-shaded areas show the slanted inshore areas. Cross section $A-A$ comprises a trapezoidal cross section, while cross section $B-B$ shows a longitudinal section along the axis of the belt drive. White lines mark the alphanumeric observation grid, and arrows mark the two release sites (inshore L, offshore $F$ ). 


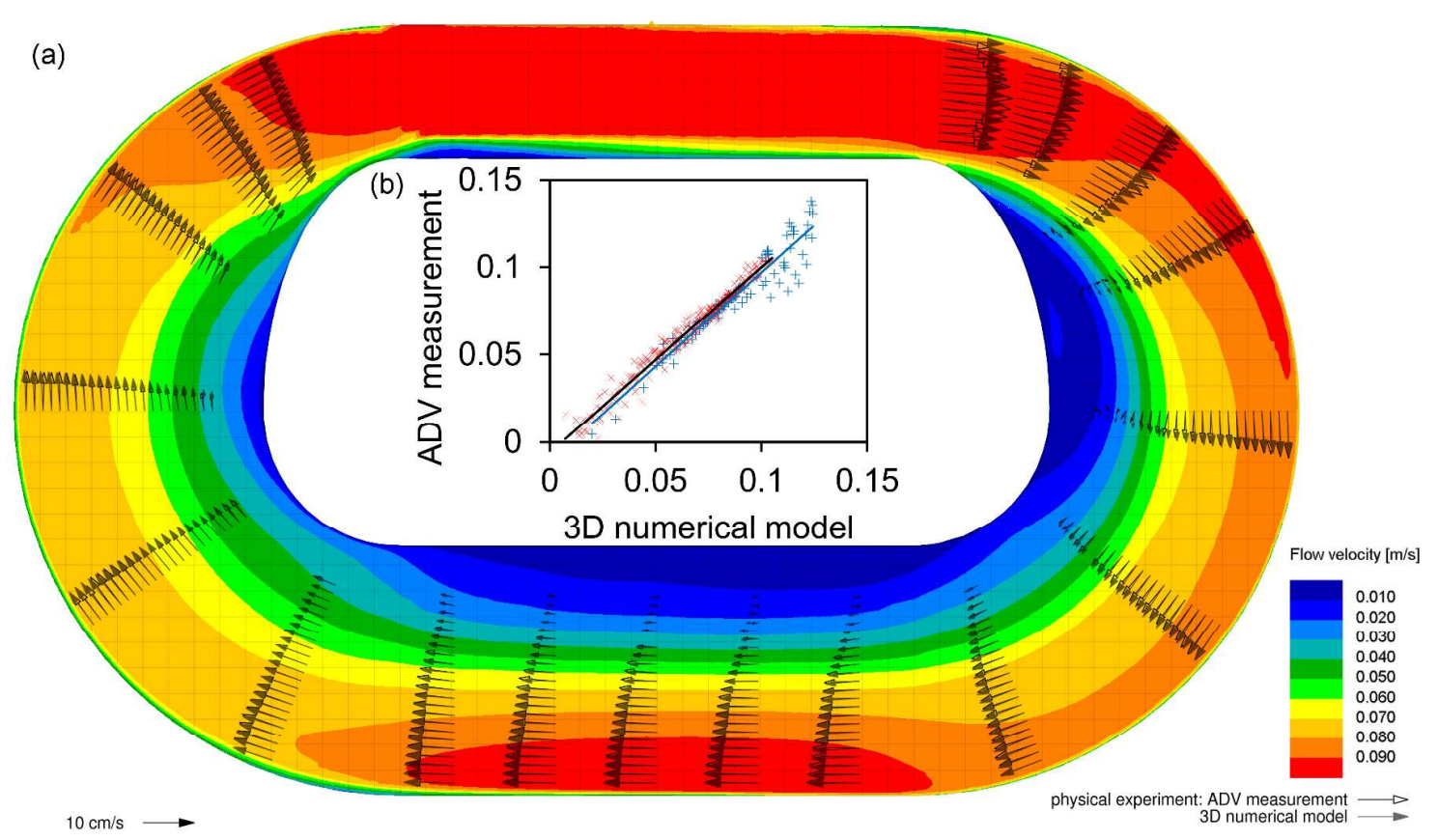

Figure 2: (a) Depth-averaged flow velocity field (contour plot) of the 3D numerical model for sub-critical flow condition (SBC) highlighting an inshore area adjacent to the inner boundary. Flow velocity vectors of: (1) ADV measurements within the physical experiment (vectors with filled arrows) and (2) flow velocity vectors of the 3D numerical model (vectors with un-filled arrows) at an elevation of $0.139 \mathrm{~m}$ (with a total water depth of $0.20 \mathrm{~m}$ in the main channel) illustrate the accordance within the 18 profiles during validation. (b) A Scatter plot of flow velocities of the 3D numerical model versus ADV measurements, where blue crosses show the six cross sections adjacent to the belt drive and red crosses indicate the remainder. Similar accordance was achieved within other elevations and flow conditions (NC, SPC). 

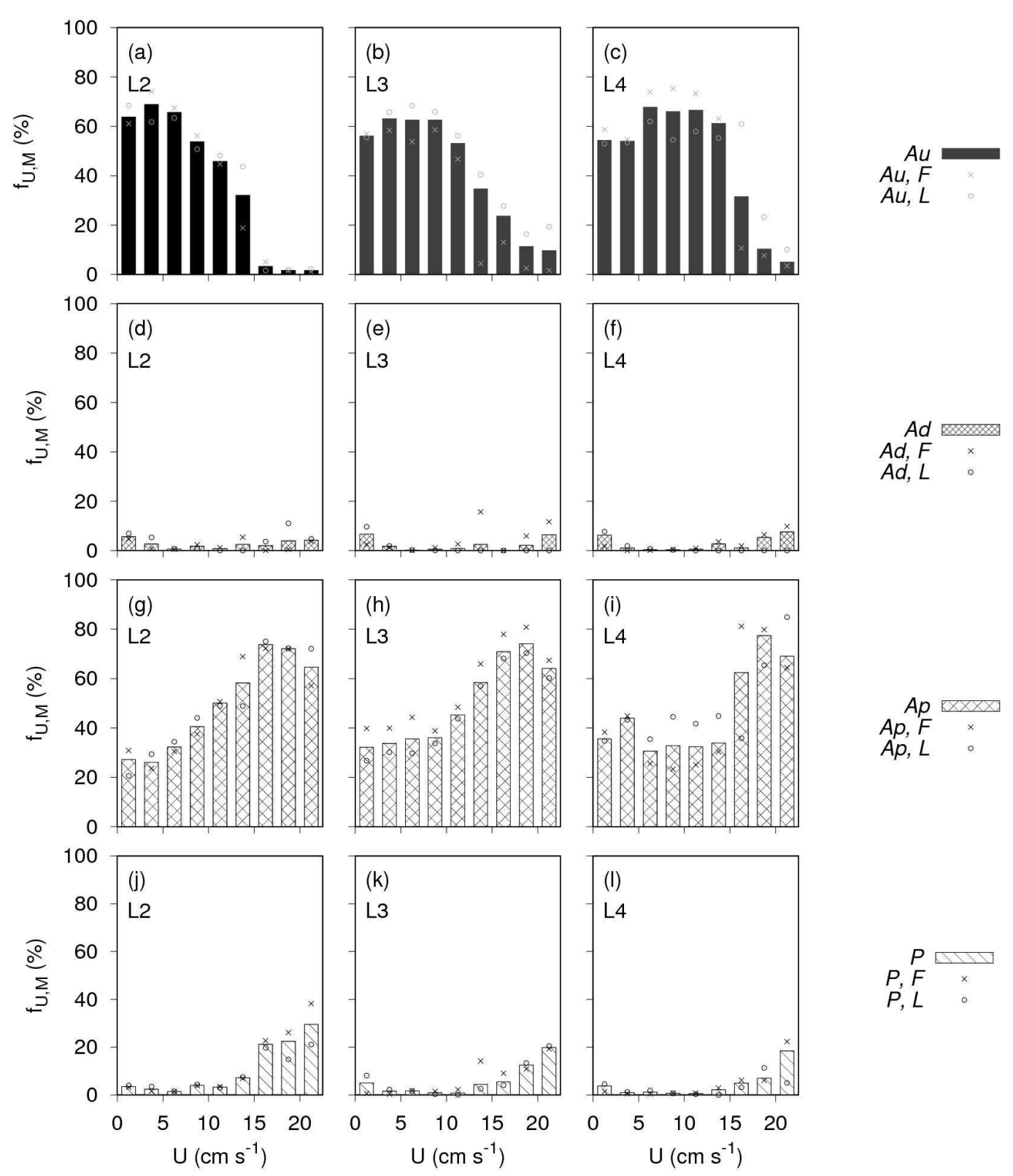

Figure 3: The results of the three-step, raster-based analysis regarding movement patterns (a-c): active upstream, (d-f): active downstream, (g-i): active-passive, and (jI): passive. Larval developmental stage $L 2$ is shown in the first column, larval stage $L 3$ in the second, and larval stage $L 4$ in the third column. Bars represent the allocation of movement patterns_-pooled for release site and diel pattern—by using a weighting factor $w_{i}$ to differentiate between upstream and downstream movement 
(step 1 of the raster-based analysis). Crosses and circles show weighted movement patterns for offshore release $(F)$ and inshore release $(L)$, respectively. 


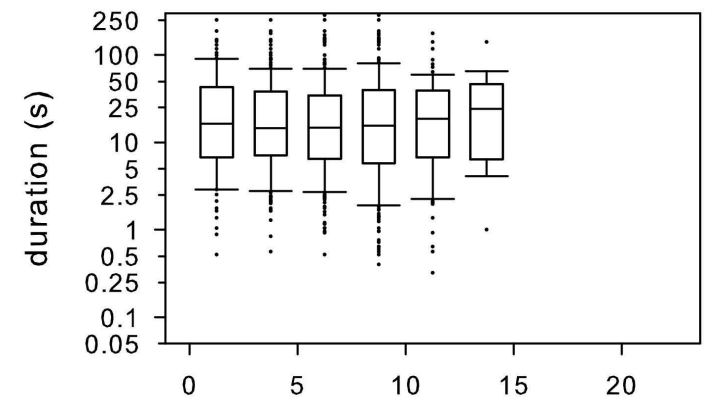

(a) flow velocity class $(\mathrm{cm} / \mathrm{s})$

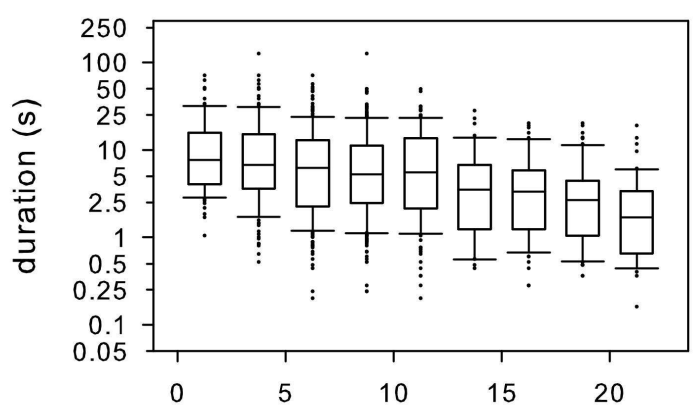

(c)

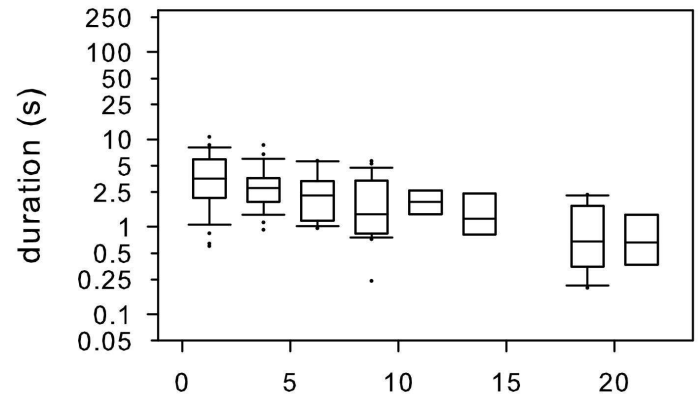

(b) flow velocity class $(\mathrm{cm} / \mathrm{s})$

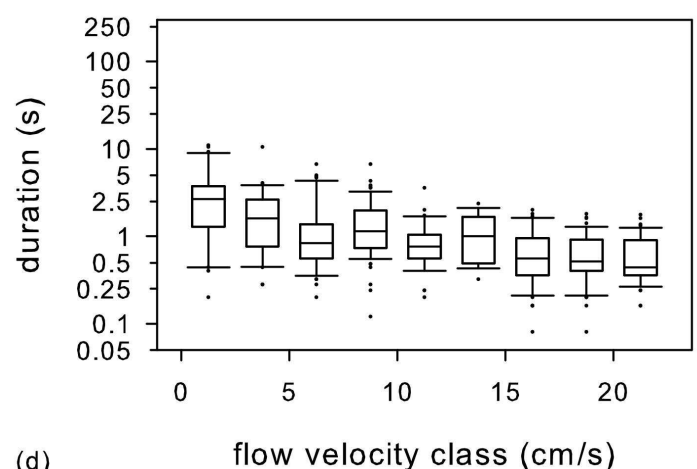

Figure 4: Boxplot diagrams of the observed durations $\Delta t_{j}$ of larvae within a certain movement pattern and flow velocity class for movement patterns (a) active upstream, (b) active downstream, (c) active-passive and (d) passive. Durations are displayed on a logarithmic scale with basis 2 . 


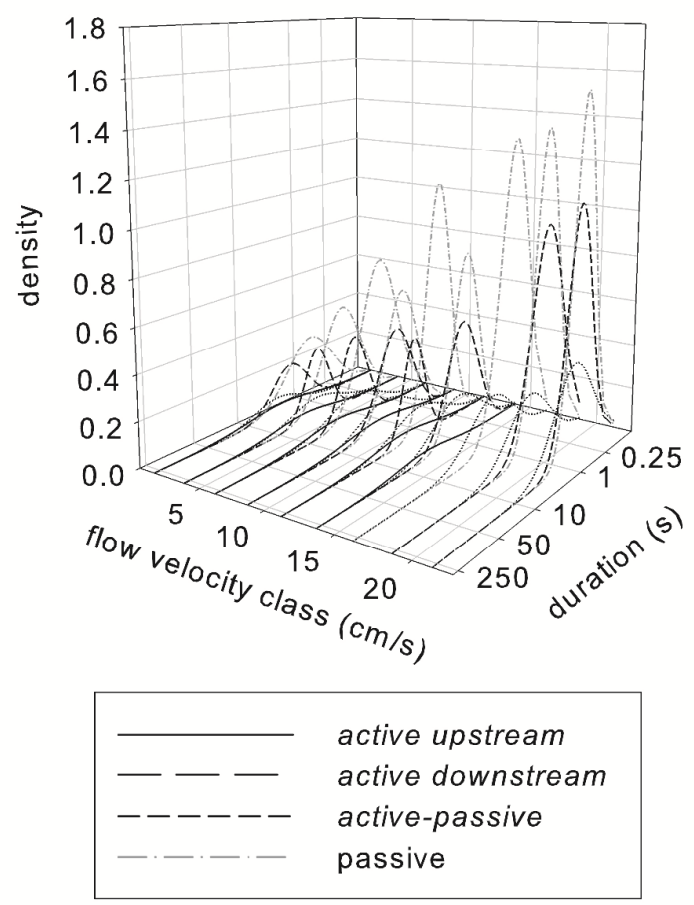

Figure 5: Fitted log-normal distributions of the durations of movement sequences $\Delta t_{j}$ (logarithmic scale) for all four movements, presented in a 3D plot for each flow velocity class. 


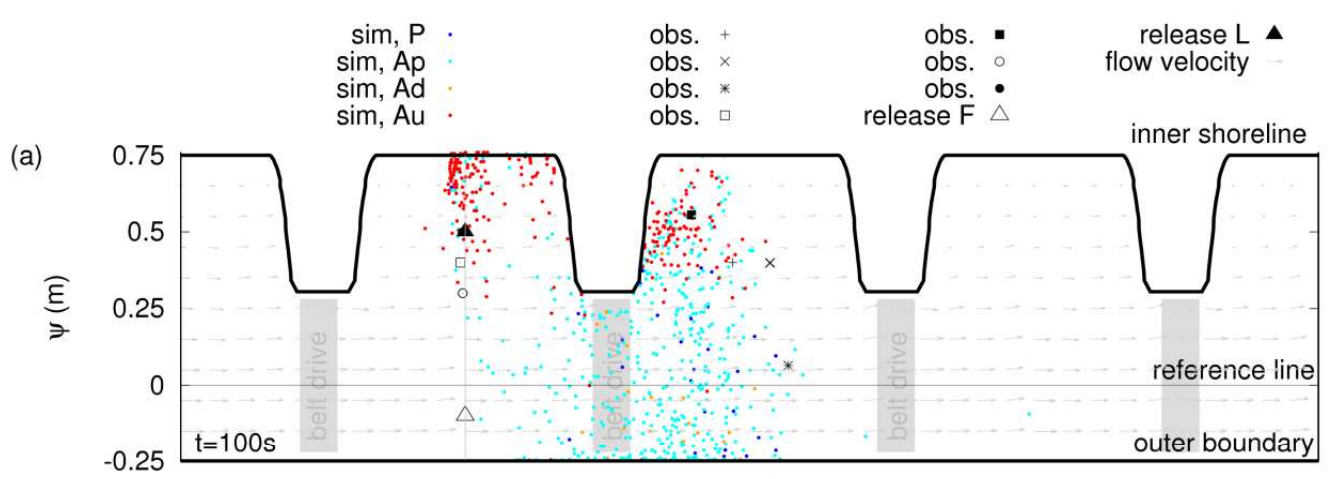

(b)

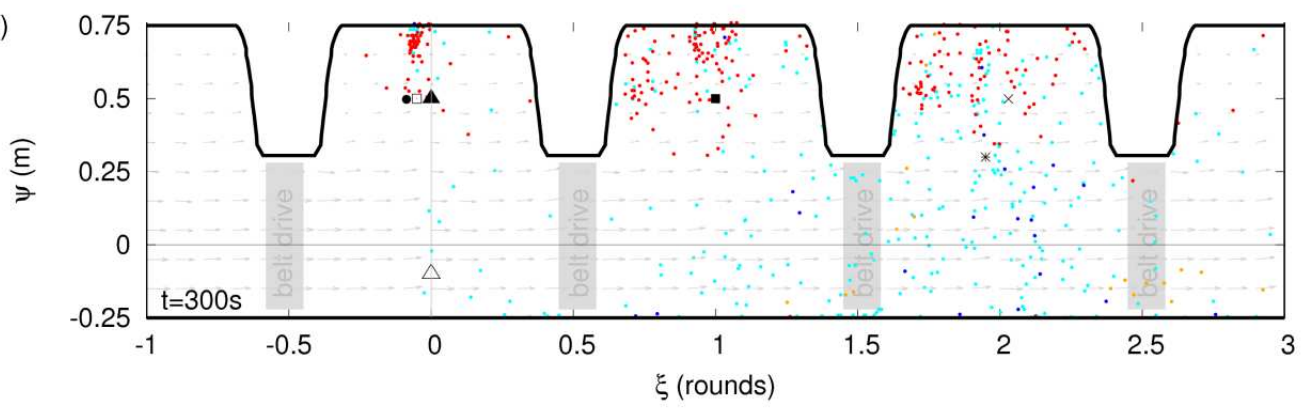

Figure 6: Validated simulation versus observed larvae for a simulation time (a) $t=100 \mathrm{~s}$ and (b) $t=300 \mathrm{~s}$, plotted with the aid of the transformed coordinates $\xi$ (rounds) and $\psi(\mathrm{m})$. Flow direction from left to right. Model parameters: $\lambda=2.0$, $\kappa=4, d_{\tau}=0.6, \theta_{c}=45^{\circ}, R_{A p}=4.05, R_{S}=0.2, S_{\max }=0.175 \mathrm{~ms}^{-1}, S_{\min }=0.01 \mathrm{~ms}^{-1}$. 

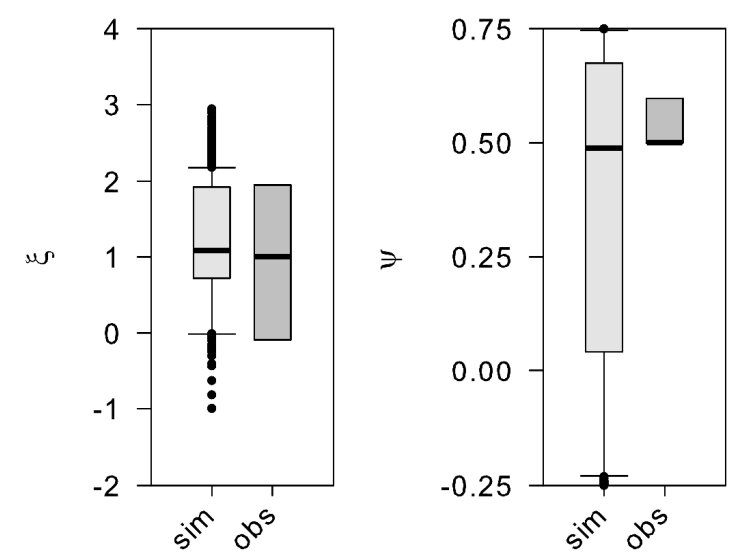

Figure 7: Boxplot of simulated versus (a) observed longitudinal drift $\xi$ (rounds) or (b) lateral divergence $\psi(\mathrm{m})$. 


\section{Appendix}

Three step, raster-based analysis of the type of movement pattern

The new method, developed to allocate the residence time of all observed larvae within each traversed grid cell (index $i$ ) of the raster-based larval trajectories to one of the four movement patterns $M$ in a three-step process, is shown in Figure $A 1$. The index $i(i \ldots n)$ represents a rising integer numbering of traversed grid cells. This analysis was applied for all traversed observation grid cells $i$ of all larval trajectories, and within all flow scenarios, to estimate the movement pattern over the experimental time. The first step of the three-step process evaluated whether the border between the actual grid cell $i$ and the next cell $i+1$ was located in the upstream region, which corresponded to the active upstream (Au) movement pattern (Fig. A2a). The upstream region was split by a line through the center of the actual grid cell $i$ and oriented perpendicular to the flow direction, to distinguish between upstream and downstream movement using a weighting factor $w_{i}$ ranging between 0 and 1 . If the border between the actual grid cell $i$ and the next cell $i+1$ was located completely in the upstream region, the weighting factor $w$ was set to 1 . If this border was completely in the downstream region, the weighting factor $w_{i}$ was set to 0 . Grid cell borders located partially in the upstream region reduced the weighting factor $w_{i}$ relative to the fraction of the border's length located in the upstream region. These instances occurred when the flow direction was not orthogonal to the observation grid (Fig. A2a) or, when there was lateral movement relative to flow direction (Fig. A2b). This method led to a probabilistic differentiation between upstream and downstream movement patterns due to the introduction of the weighting factor $w_{i}$. Residence times of larva $\left(T_{L, i}\right)$ within traversed grid cells $i$, allocated to active upstream movement pattern $T_{L, M=A u, i}$, were calculated by: 


$$
T_{L, M=A u, i}=T_{L, i} \cdot W_{i}
$$

In the second step, eleven passive numerical particles (Tritthart et al. 2009) were released, equally distributed along the border from the previous grid cell $i-1$ to the actual grid cell $i$ (Fig. A2c). Regarding diagonal movements, five particles were released on each of the two adjacent grid cell borders within a radial distance of $0.025 \mathrm{~m}$ measured from the intersection of the previous and the actual grid cell. The mean residence time of these passive numerical particles $\overline{T_{p, i}}$ within the actual grid cell was compared to the residence time $T_{L, i}$ of the larva. A residence time of the larva greater than the residence time of a passive numerical particle $\overline{T_{p, i}}$, led to the allocation of larval residence times within traversed grid cells $i$ to the movement active-passive $(M=A p)$, calculated by:

$$
T_{L, M=A p, i}=T_{L, M=A u, i}-T_{L}\left(T_{L, i} \leq \overline{T_{p, i}}\right)
$$

where $T_{L}\left(T_{L, i} \leq \overline{T_{p, i}}\right)$ indicated a residence time of a larva less than or equal to the mean residence time of the eleven released passive particles $\overline{T_{p, i}}$. Thus, $T_{L, M=A p, i}$ corresponded to a movement where a larva was drifting downstream, but resisted flow to some extent.

The third step of the analysis investigated the larva orientation towards the flow (rheotaxis) at the entry point of a traversed grid cell, where an orientation relative to flow direction was detected during video analysis. Remaining larval residence time $T_{L}\left(T_{L, i} \leq \overline{T_{p, i}}\right)$ was allocated to the active downstream $(M=A d)$ movement pattern $\left(T_{L, M=A d, i}\right)$, when negative rheotaxis (orientation in flow direction $\pm 45^{\circ}$ angular deviation to flow direction) was prevalent. If rheotaxis did not occur (orientation 
greater than $\pm 45^{\circ}$ angular deviation to flow direction) the passive $(M=P)$ movement was allocated $\left(T_{L, M=P, i}\right)$ from the remaining larval residence time $T_{L}\left(T_{L, i} \leq \overline{T_{p, i}}\right)$.

Finally, each traversed observation grid cell $i$ was classified by the magnitude of flow velocity across the grid cell using an interval of $0.025 \mathrm{~m} \mathrm{~s}^{-1}$ (nine flow velocity classes: $0 \leq \mathrm{U} \leq 0.225 \mathrm{~m} \mathrm{~s}^{-1}$ ). Allocated larval residence times were summed for each movement pattern within each flow velocity class, and divided by the sum of the residence time within the corresponding flow velocity class. Specifically, the fraction of a movement pattern within a flow velocity class $f_{U, M}$ was defined as:

$$
f_{U, M}=\frac{\sum_{i=1}^{n} T_{L, M, U, i}}{\sum_{i=1}^{n} T_{L, U, i}}
$$

where $T_{L, M, U, i}$ represented larval residence time within a traversed observation grid cell $i$ allocated to a certain movement pattern $M$ within a certain velocity class $U$, where $T_{L, U, i}$ was defined as the residence time within a certain flow velocity class $U$. Thus, the fraction $f_{U, M}$ indicated a probability of a movement pattern dependent on flow velocity and was considered as an input for the generalised linear model (GLM) and for the rheoreaction-based CRW model (RCRW) model.

Due to the implementation of the weighting factor $w$, a deterministic separation of each traversed grid cell $i$ from a certain movement pattern was not realised, to permit generalisation of the result regarding the type of movement pattern. Since this deterministic separation was required for the evaluation of the durations of movement patterns (a further input for the developed RCRW model), an adaptation was applied. Here, the movement pattern within a grid cell $i$ was distributed to the type for which a higher weighting factor $w$ could be determined. For the special case, shown in Figure A2b, where lateral movement according to the flow direction 
occurred in combination with a flow direction orthogonal to the observation raster (weighting factor received the value $w_{i}=0.5$ as the border between cell $i$ and $i+1$ had the same length for both upstream and downstream assignment of movement directions), the movement pattern $M$ for the traversed grid cell $i$ was set to the type occurring within the next traversed grid cell $i+1$. 


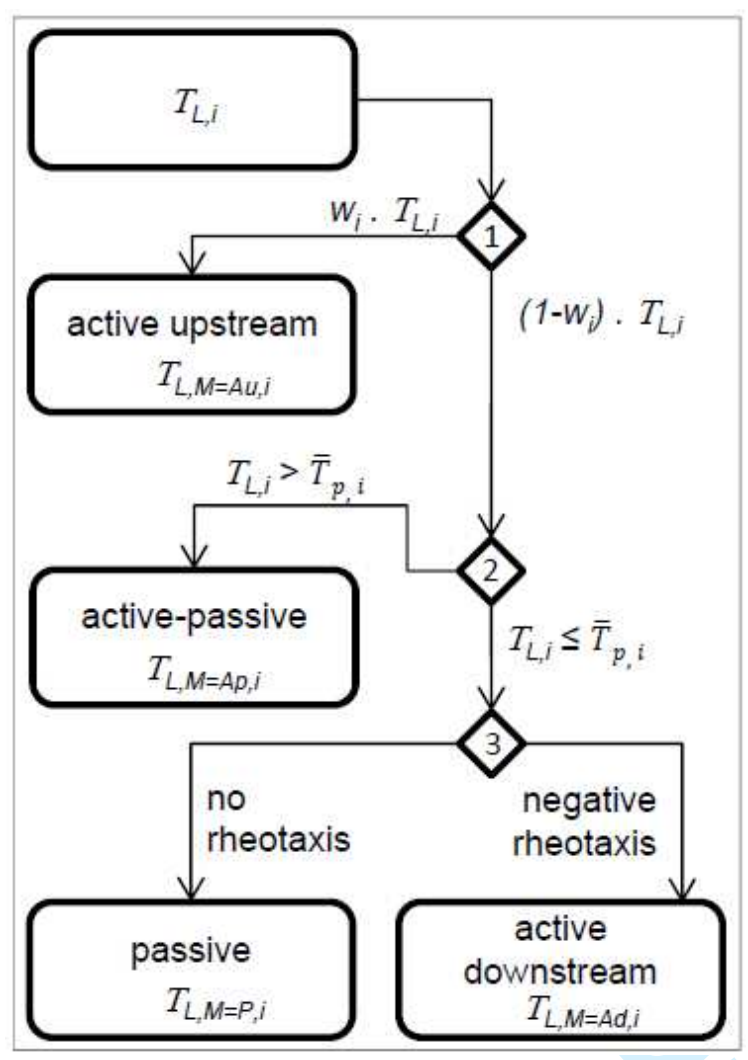

Figure A1: The flow chart describes the raster-based method used to classify movement patterns of observed larvae. Larval residence time $T_{L, i}$ is allocated to a movement pattern in a three-step process (diamonds $1,2,3$ ) for each traversed grid cell $i$ of the observed larval trajectories by using the weighting factor $w_{i}$, the mean residence time of a numerical particle $\overline{T_{p, i}}$ and the criteria "rheotaxis". 
a)

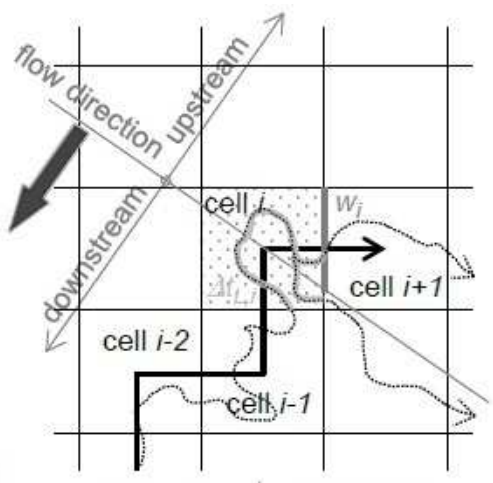

b)

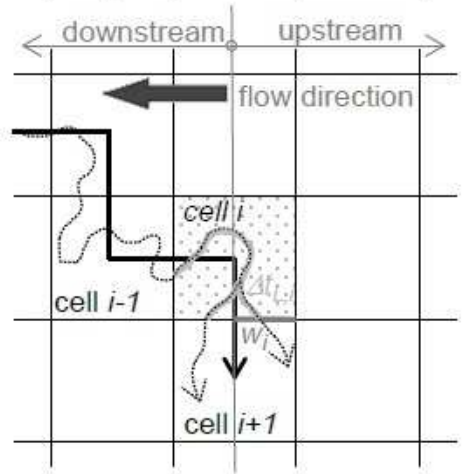

b)

.)

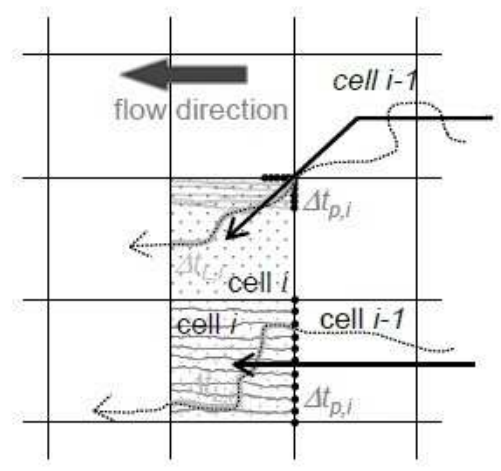

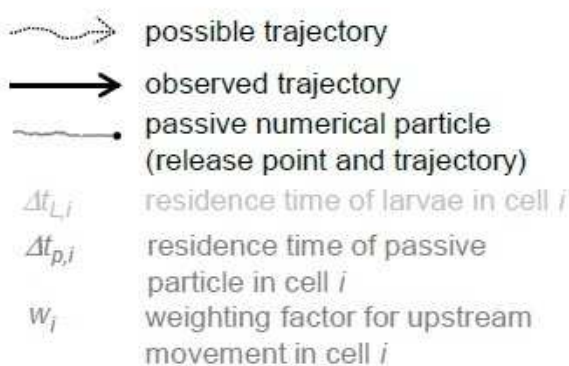

Figure A2: Schematic sketches of relevant movement instances of the three-step, raster-based analysis for: (a) upstream movement (step 1), (b) lateral movement (step 1), and (c) two cases of downstream movements: diagonal and orthogonal (step 2). 